\title{
Current (2009) State-of-the-Art Hydrogen Production Cost Estimate Using Water Electrolysis
}

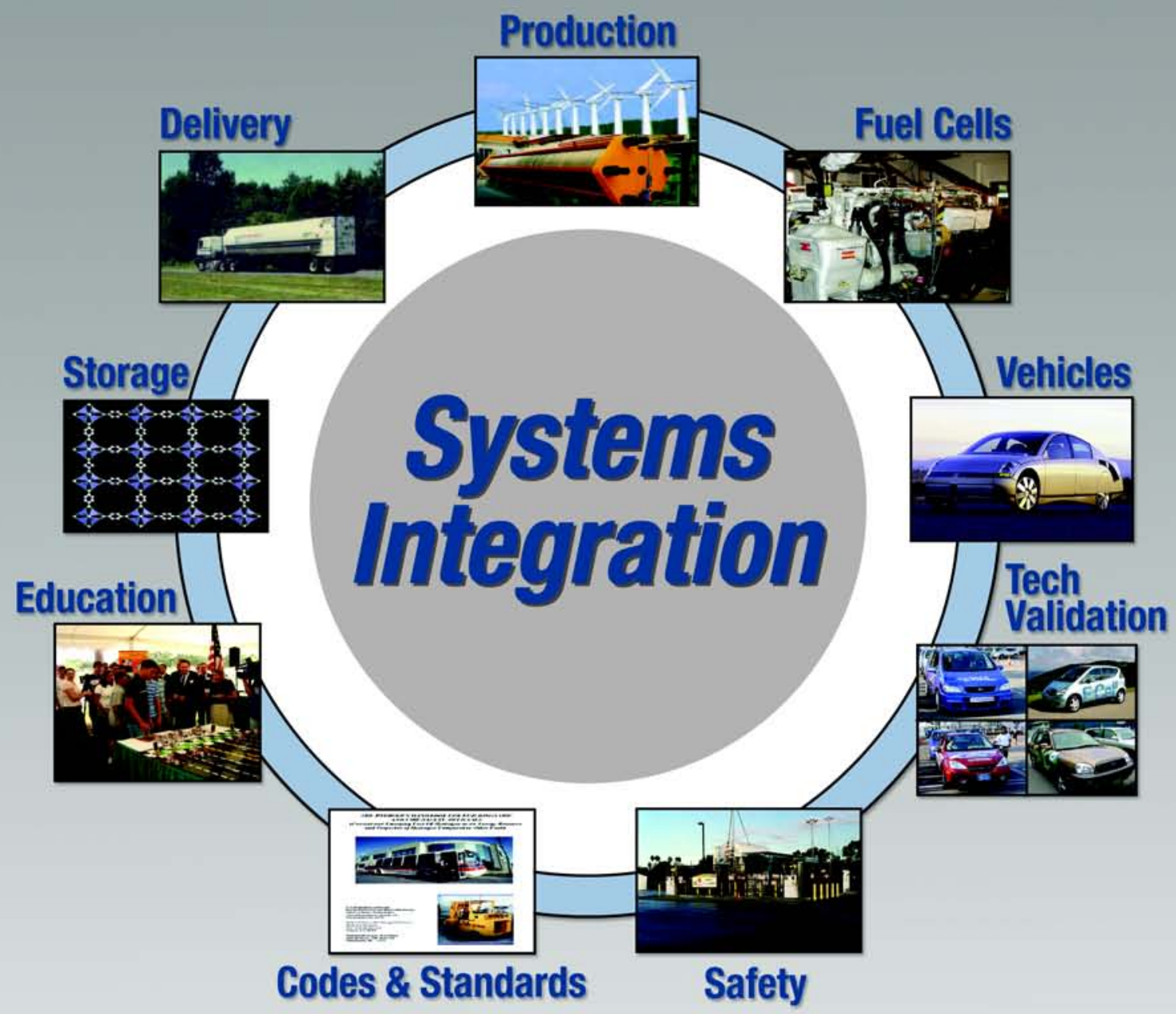

\section{Independent Review}

Published for the U.S. Department of Energy Hydrogen Program

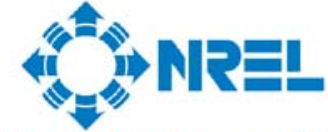

National Renewable Energy Laboratory Innovation for Our Energy Future
National Renewable Energy Laboratory

1617 Cole Boulevard • Golden, Colorado 80401-3393

303-275-3000 • www.nrel.gov

NREL is a national laboratory of the U.S. Department of Energy, Office of Energy Efficiency and Renewable Energy, operated by the Alliance for Sustainable Energy, LLC Contract No. DE-AC36-08-G028308 


\section{NOTICE}

This report was prepared as an account of work sponsored by an agency of the United States government. Neither the United States government nor any agency thereof, nor any of their employees, makes any warranty, express or implied, or assumes any legal liability or responsibility for the accuracy, completeness, or usefulness of any information, apparatus, product, or process disclosed, or represents that its use would not infringe privately owned rights. Reference herein to any specific commercial product, process, or service by trade name, trademark, manufacturer, or otherwise does not necessarily constitute or imply its endorsement, recommendation, or favoring by the United States government or any agency thereof. The views and opinions of authors expressed herein do not necessarily state or reflect those of the United States government or any agency thereof.

Available electronically at http://www.osti.gov/bridge

Available for a processing fee to U.S. Department of Energy and its contractors, in paper, from:

U.S. Department of Energy

Office of Scientific and Technical Information

P.O. Box 62

Oak Ridge, TN 37831-0062

phone: 865.576 .8401

fax: 865.576 .5728

email: mailto:reports@adonis.osti.gov

Available for sale to the public, in paper, from:

U.S. Department of Commerce

National Technical Information Service

5285 Port Royal Road

Springfield, VA 22161

phone: 800.553 .6847

fax: 703.605.6900

email: orders@ntis.fedworld.gov

online ordering: http://www.ntis.gov/ordering.htm

Printed on paper containing at least $50 \%$ wastepaper, including $20 \%$ postconsumer waste 


\section{List of Acronyms}
AEO
EIA Annual Energy Outlook
BOP
$\mathrm{CF}$
balance of plant
$\mathrm{C} / \mathrm{S} / \mathrm{D}$
capacity factor
compression, storage, and dispensing
DOE
U.S. Department of Energy
DSM
dimensionally stable membrane
EIA
Energy Information Administration
FTE
full-time equivalent
GHG
greenhouse gas
$\mathrm{H} 2 \mathrm{~A}$
DOE Hydrogen Analysis
HDSAM
H2A Delivery Hydrogen Scenario Model
HFCIT
U.S. Department of Energy, Hydrogen, Fuel Cells
HHV
and Infrastructure Technologies
$\mathrm{KOH}$
higher heating value
LHV
potassium hydroxide
NREL
O\&M
lower heating value
National Renewable Energy Laboratory
PEM
R\&D
SPE
operations and maintenance
polymer electrolyte membrane/proton exchange membrane
research and development
solid polymer electrolyte 


\section{Independent Review Panel Summary Report}

September 30, 2009

From: Independent Review Panel, Hydrogen Production Cost Estimate Using Water Electrolysis

To: $\quad$ Mr. Mark Ruth, NREL, DOE Hydrogen Systems Integration Office

Mr. Todd Ramsden, NREL, Hydrogen Technologies and Systems Center

Subject: Independent Review Panel Summary Report

Per the tasks and criteria of the Independent Review Charter of December 22, 2008, this is the Independent Review Panel's unanimous technical conclusion, arrived at from data collection, document reviews, interviews, and deliberations from February 2009 through June 2009. All reported hydrogen costs include a real 10\% internal rate of return on investments and are expressed in 2005 reference-year dollars. For central production, the hydrogen cost is at the plant gate of an electrolysis facility with a capacity of $50,000 \mathrm{~kg} / \mathrm{day}$. For distributed production the electrolysis unit is located at a forecourt refueling site and has a design capacity of $1,500 \mathrm{~kg} /$ day. The distributed hydrogen cost includes both the production cost and the cost of compression, storage, and dispensing.

\section{Conclusions}

- The current (2009) state-of-the-art cost for delivered hydrogen from electrolysis for a forecourt refueling station ranges from $\$ 4.90 / \mathrm{kg}-\mathrm{H}_{2}$ to $\$ 5.70 / \mathrm{kg}-\mathrm{H}_{2}$ dispensed at the pump, with a base-case estimate of $\$ 5.20 / \mathrm{kg}-\mathrm{H}_{2}$. This base-case estimate of $\$ 5.20 / \mathrm{kg}-\mathrm{H}_{2}$ includes an electrolysis production cost of $\$ 3.32 / \mathrm{kg}-\mathrm{H}_{2}$ and compression, storage and dispensing costs of $\$ 1.88 / \mathrm{kg}-\mathrm{H}_{2}$. These costs are evaluated using EIA Annual Energy Outlook (AEO) 2005 High A Case industrial electricity costs (\$0.053/kWh on average).

- The current (2009) state-of-the-art plant gate cost for hydrogen from a central electrolysis operation ranges from $\$ 2.70 / \mathrm{kg}-\mathrm{H}_{2}$ to $\$ 3.50 / \mathrm{kg}-\mathrm{H}_{2}$ with a base-case estimate of $\$ 3.00 / \mathrm{kg}-\mathrm{H}_{2}$. These costs are evaluated at an assumed renewable-based electricity cost of $\$ 0.045 / \mathrm{kWh}$, which was supplied to the Panel by DOE and based on wind-generated electricity.

- Significant technology advancements in reducing capital costs and improving efficiency have lead to substantially improved electrolysis production costs compared to DOE's H2A assessment of 2005 technology costs (forecourt production at $\$ 6.05 / \mathrm{kg}$ and central production at $\$ 4.50 / \mathrm{kg}$ ). Current stateof-the-art electrolysis conversion efficiency is $67 \%$ (LHV), only slightly less than the DOE 2014 target of $69 \%$. Electrolyzer capital costs are expected to fall to $\$ 380 / \mathrm{kW}$ for forecourt production systems and $\$ 460 / \mathrm{kW}$ for central production facilities, compared to the DOE 2014 targets of $\$ 400 / \mathrm{kW}$ and $\$ 350 / \mathrm{kW}$, respectively.

\section{Rationale}

Based on its electrolyzer experience and investigations into current state-of-the-art electrolyzer technologies, the Panel has determined that recent advances in electrolyzer technologies are expected to result in reduced capital costs and improved conversion efficiency. These technology advances are either ready for commercial development or could be commercialized within about four years. As part of its examination of electrolyzer technologies, the Panel reviewed the available information concerning electrolysis technologies and gathered feedback from electrolyzer suppliers and developers. The Panel examined annual and final reports from DOE-funded principal investigators as well as other general electrolysis reports and relevant literature. The Panel also had discussions with electrolyzer companies regarding their new technology developments, laboratory-scale electrolyzer demonstrations, and 
commercial offerings. Innovations and advancements presented to the Panel by electrolyzer companies support the significant reduction in capital costs and efficiency improvement expressed in this report. Advancements have been made in both proton exchange membrane (PEM) and alkaline electrolyzers and the cost and efficiencies of both approaches overlap, with neither having a clear advantage over the other.

To arrive at hydrogen costs for central and distributed production using water electrolysis, the Panel used the DOE H2A Production model modified to reflect current state-of-the-art electrolysis technologies. Specifically, the Panel used the DOE-published H2A cases for forecourt and central electrolysis production representing 2005 technology as a starting point. All of the inputs were reviewed and were modified as appropriate based on the Panel's experience and its evaluation of information gathered from electrolyzer developers. Using these modified H2A cases for forecourt and central electrolysis, the Panel developed base-case cost results for current 2009 state-of-the-art technology. The Panel also performed a sensitivity analysis to express the uncertainty in its base-case values to arrive at a range for the results.

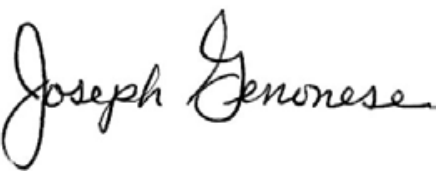

Mr. Joe Genovese

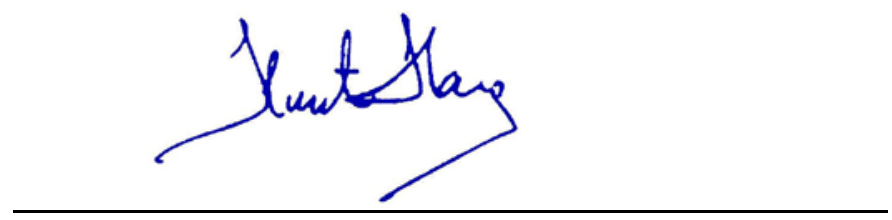

Mr. Knut Harg

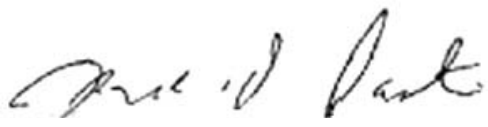

Mr. Mark Paster

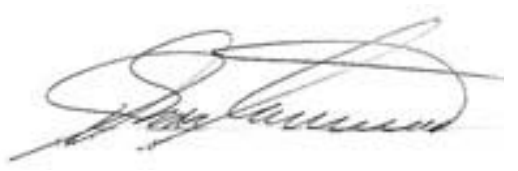

Dr. John Turner 


\section{Table of Contents}

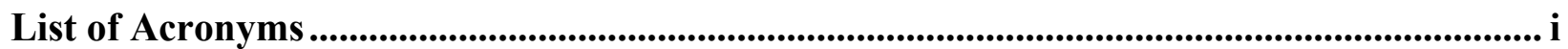

Independent Review Panel Summary Report ............................................................................. ii

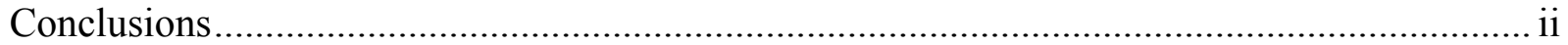

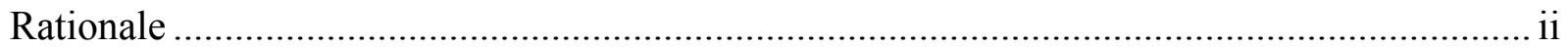

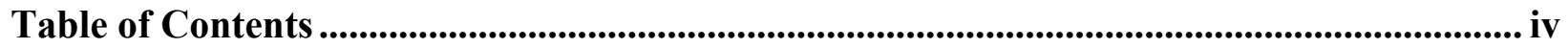

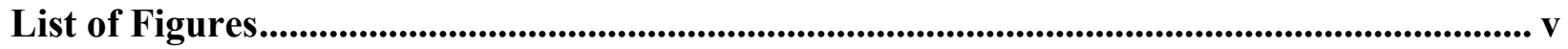

List of Tables ........................................................................................................................................ v

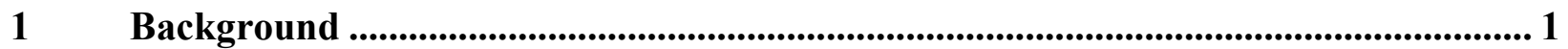

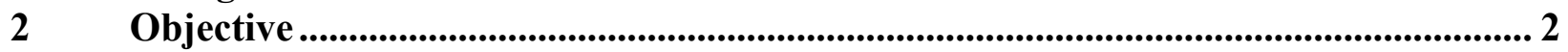

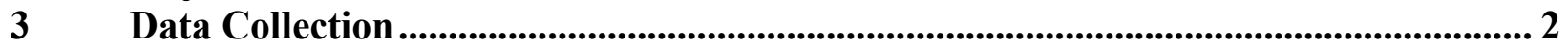

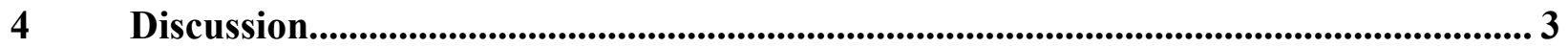

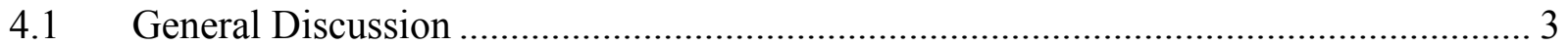

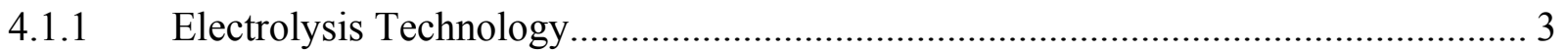

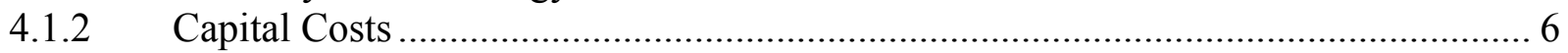

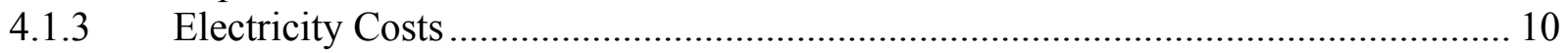

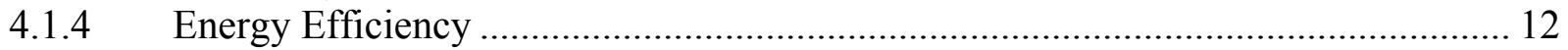

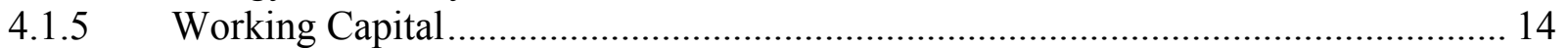

4.2 Forecourt Electrolysis ..................................................................................... 14

4.2.1 Capacity Factor and Storage ...................................................................... 14

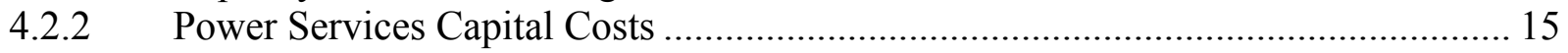

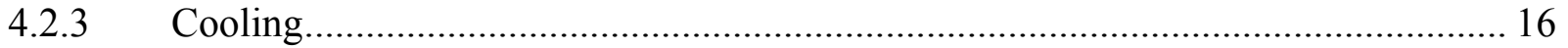

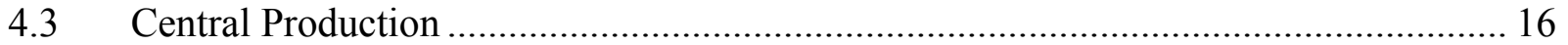

4.3.1 Capacity Factor (Central Plant) ....................................................................... 16

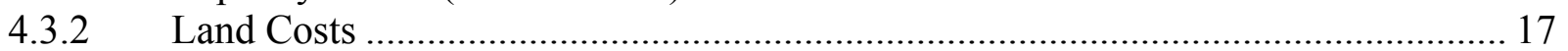

4.3.3 Power Services Capital Costs ............................................................................ 17

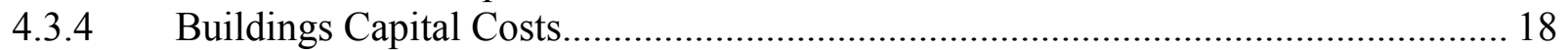

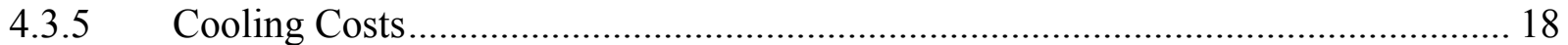

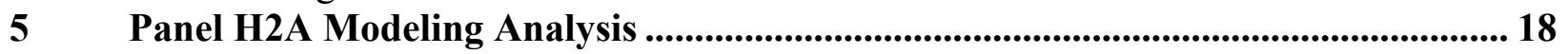

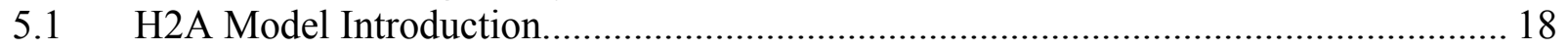

5.2 H2A Modeling Analyses Provided ........................................................................... 19

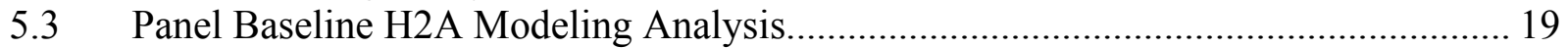

5.3.1 Distributed Forecourt Production Base Case ........................................................ 19

5.3.2 Central Production Base Case ............................................................................... 21

5.4 Sensitivity Analysis ............................................................................................ 23

5.4.1 Distributed Forecourt Production Sensitivity Analysis ...................................... 23

5.4.2 Central Production Sensitivity Analysis ........................................................... 25

6 Results and the Impact of Electricity Prices......................................................... 27

$7 \quad$ Opportunities for Future Cost Reductions............................................................................ 28

Appendix A. Vendor Questionnaire and Fact Sheet................................................................ 30

Appendix B. Capacity Factor and Storage ............................................................................. 36

Appendix C. Reviewer Biographies............................................................................................... 43 


\section{List of Figures}

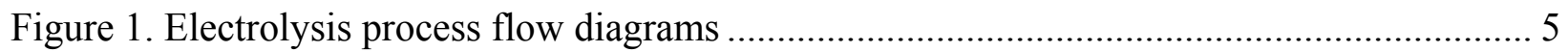

Figure 2. Vendor capital cost information (in 2005 reference-year dollars) ................................. 9

Figure 3. Influence of electricity cost alone on hydrogen cost

(without capital, operating, or maintenance costs) ……........................................... 10

Figure 4. Average industrial price for electricity by state ......................................................... 11

Figure 5. Historical variation in the average retail rate for the industrial sector ........................ 12

Figure 6. Forecourt electrolysis Panel base case sensitivity analysis tornado chart ...................... 24

Figure 7. Forecourt production (excluding forecourt C/S/D) - hydrogen cost breakdown.......... 25

Figure 8. Central electrolysis Panel base case sensitivity analysis tornado chart........................... 26

Figure 9. Central production hydrogen cost breakdown............................................................ 26

Figure 10. Base cases as a function of electricity price ................................................................. 28

Figure 11. Seasonal demand variation and scheduled outage...................................................... 37

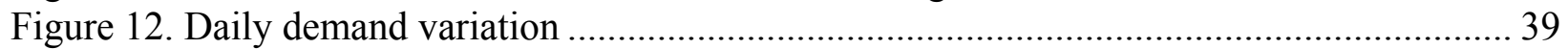

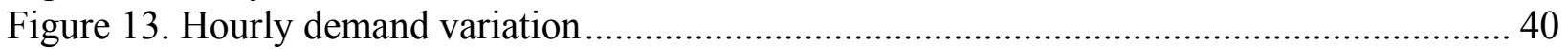

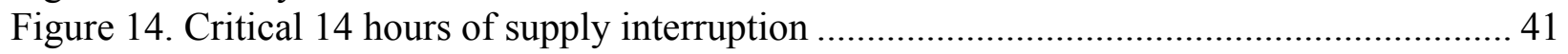

\section{List of Tables}

Table 1. Commercial or Near-Commercial Hydrogen Production PEM and

Alkaline Electrolysis Technology ………................................................................ 3

Table 2. Key Parameters for the Forecourt Production Unit Capacity Factor .............................. 15

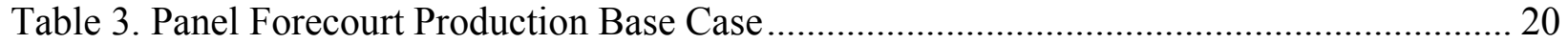

Table 4. Panel Central Production Base Case........................................................................... 22

Table 5. Forecourt Electrolysis Panel Base Case Sensitivity Analysis ......................................... 24

Table 6. Central Electrolysis Panel Base Case Sensitivity Analysis ............................................ 25 


\section{Background}

The mission of the U.S. Department of Energy (DOE) Hydrogen Program is to research, develop, and validate fuel cell and hydrogen production, delivery, and storage technologies. Hydrogen from diverse domestic resources then can be used in a clean, safe, reliable, and affordable manner in fuel cell vehicles and stationary power applications. The Hydrogen Program measures progress against the research and development (R\&D) technical targets it established in conjunction with industry partners. Additionally, it commissions independent verifications of progress made towards meeting key technical targets. These verifications provide an unbiased view of the program's progress that is based on the input of independent technical experts. Understanding this unbiased information is critical to program decision making; budget planning; and prioritization of research, development, and demonstration activities. The verifications help to ensure the quality, objectivity, utility, and integrity of information disseminated to the public. As such, they improve confidence in the results and conclusions that DOE and other stakeholders reference in technical and program publications, announcements, Congressional testimony, and other arenas.

The National Renewable Energy Laboratory (NREL) Systems Engineering \& Program Integration Office (Systems Integrator) was tasked by the U.S. Department of Energy Hydrogen, Fuel Cells and Infrastructure Technologies (HFCIT) Program Manager to commission an independent review to estimate the current (2009) state-of-the-art hydrogen production cost using water electrolysis systems. The NREL Systems Integrator is responsible for conducting independent reviews of progress toward meeting the HFCIT Program technical targets. Since 2005, the HFCIT Program has provided funding for projects to improve performance and to reduce the cost of hydrogen production using water electrolysis. Hydrogen production cost estimates for the state-of-the-art technology as it exists today are required for gauging the progress that industry and these DOE-funded projects have made, and to provide guidance on the direction of future R\&D funding.

This review examines alkaline and polymer electrolyte membrane (PEM) water electrolyzers, as requested by DOE. The hydrogen production cost review includes both distributed and central production. For distributed production, the electrolyzer is located at a refueling site and has a design capacity of $1,500 \mathrm{~kg} /$ day. The hydrogen cost includes both the production cost and the cost of storage, compression, and dispensing (C/S/D). The Independent Review Panel (the Panel) focused on the cost of production, using the $\mathrm{C} / \mathrm{S} / \mathrm{D}$ costs as outlined in DOE's H2A Current Forecourt Hydrogen Production from Grid Electrolysis (1,500 kg per day) version 2.1.2. The Panel only modified the amount of storage based on its analysis of the electrolysis capacity factor and site storage needs. For central production, the hydrogen cost is at the plant gate of an electrolysis operation with a $50,000 \mathrm{~kg} /$ day capacity. The review assumes that the plant is supplied electricity based on renewable energy and has a high operating capacity factor limited only by the performance of the electrolyzers.

This report provides the results of the Independent Review Panel's examination of the progress in meeting water electrolysis cost targets for distributed and centralized facilities. It also provides perspective on the cost of hydrogen from today's (2009) "state-of-the-art" distributed and central production technology. The key cost drivers for hydrogen production from electrolysis are capital cost and electricity use. The progress made on these cost drivers can be compared with 
the DOE targets for these variables. Jointly with DOE, the Panel has defined "state of the art" as technology that has been demonstrated to at least some degree at a laboratory scale or larger and that could be commercialized within about a four-year timeframe. The estimate of the current state-of-the-art technology is compared to that published in the DOE Hydrogen Analysis (H2A) version 2 electrolysis cases, ${ }^{1}$ which were based on 2005 technology.

It is difficult to compare the Panel's results with the DOE Hydrogen Program overall cost targets for water electrolysis. These targets were established utilizing the H2A Production version 1 models. The H2A Forecourt Production Model version 2 has significantly improved knowledge of the costs of $\mathrm{C} / \mathrm{S} / \mathrm{D}$, and includes other improvements which add significantly to the cost of hydrogen. The H2A central production electrolysis cases used to generate the DOE central electrolysis targets are based on an integrated wind and electrolysis operation that produces $50,000 \mathrm{~kg}$ per day on average, but which has a low electrolyzer operating capacity factor of $58 \%$ due to wind variability. This is very different from the central electrolysis-production case the Panel was asked to examine.

\section{Objective}

The objective of this project is to obtain a consensus technical conclusion from a panel of independent industry experts with regard to the estimated current (2009) state-of-the-art cost of producing hydrogen from both alkaline and PEM water electrolyzers for distributed and central production.

\section{Data Collection}

Initial sources of information for the Panel's independent review were provided by the DOE, and included information such as annual and final reports from project principal investigators, comments provided by Annual Merit Reviewers and the FreedomCAR and Fuel Partnership's Hydrogen Production Tech Team on the research and development (R\&D) projects, and other general electrolysis reports and information. The Panel supplemented this information using literature research, examination of project data and status reports, interviews with technical experts, discussions with applicable organizations/individuals, and data requests.

To facilitate data collection, an Industry Questionnaire and an Electrolysis Fact Sheet were prepared (see Appendix A) and sent to interested suppliers. The Fact Sheet includes an explanation of the goals of the data request followed by a list of specific technology, capital cost, and production questions covering data items required for the H2A modeling analysis. For distributed hydrogen production, the cost for compression, storage, and dispensing $(\mathrm{C} / \mathrm{S} / \mathrm{D})$ was taken from the DOE-published H2A version 2 case, with only a minor adjustment as indicated in Section 4.2.1, Capacity Factor and Storage (below).

Table 1 provides a top-level summary of current commercial or near commercial hydrogen PEM and alkaline electrolysis technologies. As shown in the table, a number of small PEM units, producing typically less than $100 \mathrm{~kg}$ of hydrogen per day, have been constructed and tested or

\footnotetext{
${ }^{1}$ Http://www.hydrogen.energy.gov/h2a_analysis.html. Accessed September 19, 2009.
} 
are in the process of being developed and built. Commercial alkaline electrolyzers that produce up to $1,000 \mathrm{~kg}$ of hydrogen per day currently are available.

All the companies listed in Table 1 were interviewed by the Panel, and all but one of these companies completed an Electrolysis Fact Sheet and had follow-up discussions with the Panel. Additionally, the Panel used data from General Electric's Advanced Alkaline Electrolysis program. The interviews and data sheets provided a great deal of very valuable information about the progress that has been made over the past five years and the current state of the art in the production of hydrogen by electrolysis. The Panel's opinion is that the progress made thus far-and which continues to be made - is impressive.

Table 1. Commercial or Near Commercial Hydrogen Production PEM and Alkaline Electrolysis Technology

\begin{tabular}{|l|c|c|c|c|}
\hline Supplier & Location & Technology & $\begin{array}{c}\text { Production } \\
\text { Capacity (kg/day) }\end{array}$ & $\begin{array}{c}\mathbf{H}_{2} \text { Product } \\
\text { Pressure (psi) }\end{array}$ \\
\hline Avalance & United States & Unipolar Alkaline & Up to 10 & Up to 6,500 \\
\hline Giner & United States & Bipolar PEM & Up to 8 & Up to 1,250 \\
\hline H2 Technologies & Norway & Bipolar Alkaline & Up to 1,000 & Atmospheric \\
\hline Hydrogenics & United States & Bipolar PEM & Up to 127 & Up to 363 \\
\hline IHT & Switzerland & Bipolar Alkaline & Up to 1,500 & Up to 464 \\
\hline Proton & United States & Bipolar PEM & Up to 13 & Up to 435 \\
\hline
\end{tabular}

\section{Discussion}

\subsection{General Discussion}

\subsubsection{Electrolysis Technology}

Hydrogen is produced via electrolysis by passing direct current through two electrodes in water. The water molecule is split, producing oxygen at the anode (positive electrode) and hydrogen at the cathode (negative electrode). Typical requirements of the electrolysis systems include electricity for electrolysis and other peripheral equipment, cooling water for the hydrogen generation unit, pre-pressurization gas, and inert gas. Three types of low temperature industrial electrolysis units currently are produced - unipolar electrolyzer, bipolar electrolyzer, and solid polymer electrolyte electrolyzer.

Alkaline electrolyzers involve using an aqueous solution of potassium hydroxide ( $\mathrm{KOH})$. This is used because of KOH's high conductivity, and because the oxygen evolution reaction has the least energy loss in this solution. These electrolyzers do not require precious metals and typically use nickel electrodes. The electrolyzer units can be either unipolar or bipolar.

A unipolar electrolyzer resembles a tank and has electrodes connected in parallel. This electrolyzer design is a high-current, low-voltage system with a single bus bar connecting all the anodes and another connecting all the cathodes. A membrane is placed between each cathode and anode; this separates the hydrogen and oxygen as the gasses are produced but allows the transfer of ions. 
The bipolar alkaline electrolyzer resembles a filter press. Electrolysis cells are connected in series; hydrogen is produced on one side of each cell and oxygen on the other side. The bipolar electrolyzer is a high-voltage, lower current device, and a membrane separates the electrodes. Most commercial alkaline systems use the bipolar design.

The third type of electrolysis unit is a solid polymer electrolyte (SPE) electrolyzer. Such systems also are referred to as proton exchange membrane or polymer electrolyte membrane (PEM) electrolyzers. In this unit the electrolyte is a solid ion conducting membrane and the electrolyzer therefore is fed with pure water. (This is in contrast to the $\mathrm{KOH}$ aqueous solution in the alkaline electrolyzers.) The traditional membrane is Nafion ${ }^{\circledR}$ and consists of a Teflon ${ }^{\circledR}$-like polymer with attached sulfonic-acid groups. The membrane allows the $\mathrm{H}^{+}$ion to transfer from the anode side of the membrane - where oxygen is produced - to the cathode side where it forms hydrogen. The SPE membrane then also serves to separate the hydrogen and oxygen gasses. This effectively is an acid environment, therefore significant precious metal ( $\mathrm{Pt}, \mathrm{Ir}, \mathrm{Ru})$ loadings are used. PEM electrolyzers typically are configured in the bipolar mode.

The technology used in the chlor-alkali industry is in many ways similar to the PEM technology, such as using similar types of ion conducting membranes and precious metal catalysts. Although there are important differences in both environment and cell structure, it is interesting to note that current chlor-alkali plants are rated at from $8 \mathrm{MW}$ to $10 \mathrm{MW}$ of power per electrolyzer, with 10 or more such units per plant. Despite lower current density than used in PEM water electrolysis (typically $600 \mathrm{~A} / \mathrm{cm}^{2}$ versus 1,000 to $2,000 \mathrm{~A} / \mathrm{cm}^{2}$ ), the rating per unit is greater than in current PEM development due to a much larger active area (typically $3 \mathrm{~m}^{2}$ versus $0.3 \mathrm{~m}^{2}$ ). Historically, however, large industrial electrolysis plants have been alkaline. The largest such plant still in operation - the KIMA fertilizer plant in Aswan, Egypt - has a reported capacity of $74,000 \mathrm{~kg} /$ day (about $150 \mathrm{MW}$ ), but all other plants with similar capacities have closed.

A typical electrolysis process diagram is shown in Figure 1. Note that different processes use different pieces of equipment. For example, PEM units do not require the $\mathrm{KOH}$ mixing tank because no electrolytic solution is needed for these electrolyzers. Another example involves water purification equipment. Water quality requirements differ across electrolyzers; some units include water purification inside their hydrogen generation unit, and others require an external deionizer or reverse-osmosis unit to purify water before it is fed to the cell stacks. The PEM units typically require much greater water purity than do the alkaline units. A water storage tank can be included to ensure that the process has adequate water available in storage, in case the water system is interrupted. Each system has a hydrogen generation unit that integrates the electrolysis stack, gas purification and dryer, and heat removal. Electrolyte circulation also is included in the electrolyzer module or is installed as a complete package. Oxygen and purified hydrogen are produced from the generation unit. 


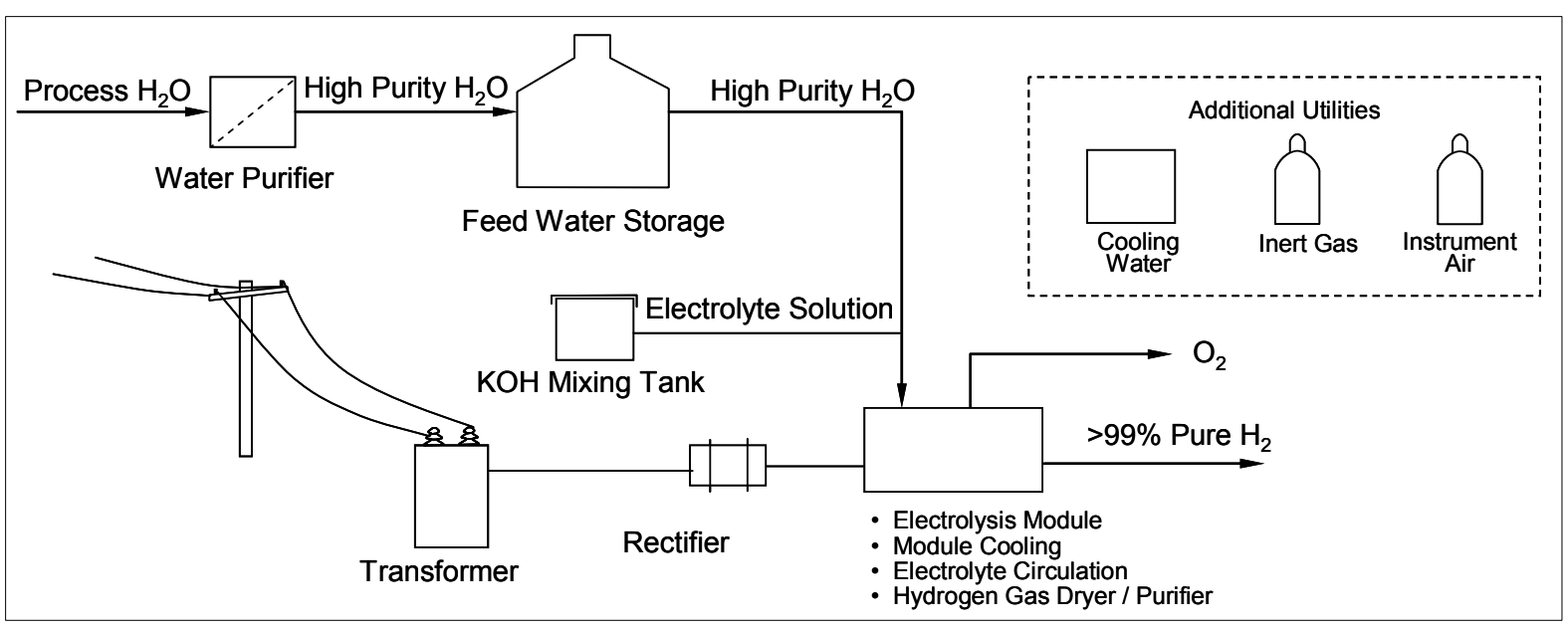

Figure 1. Electrolysis process flow diagrams

Since the last milestone report was written, ${ }^{2}$ PEM electrolyzer suppliers have continued to focus development efforts on reducing capital costs and improving efficiency. New material choices have been incorporated and cell structures have been simplified to reduce cost and increase manufacturability. An example of this is stamped metal bipolar plates. A spin-off from advancing hydrogen fuel cell technology, current development is directed at meeting the twentyfold increased life requirement of the electrolysis application and providing the cost leverage of replacing the machined cell configurations. Cell design also has benefited from dimensional changes directed at increasing cell active area and reducing cell resistance, thus increasing efficiency.

In addition to these cell hardware improvements, PEM suppliers have developed thinner, more robust membranes including, in some cases, shifts from solid Nafion ${ }^{\circledR}$ to composite membrane configurations. To improve electrolyzer efficiency, and thereby reduce operating and capital costs, an advanced thin rigid polymer supported membrane having resistance comparable to that of a 0.002 inch thick Nafion ${ }^{\circledR} 112$ membrane - but with significantly improved mechanical properties - is being tested. This advanced membrane is referred to as a dimensionally stable membrane (DSM) because the membrane support minimizes changes in membrane dimensions (swelling/contraction) with changes in water content.

The PEM electrode assemblies traditionally use high noble metal catalyst loadings. These electrodes provide high performance and reliability but they are very expensive, particularly with the present high cost of platinum. Catalyst formulations have been altered, and reduced catalyst loadings are being validated to lower costs yet still provide the required system life and electrolyzer performance. Suppliers are applying recent developments in fuel cell catalyst technology to the electrolyzer electrodes. For example, a new cathode consisting of platinum supported on carbon black catalyst blended with Nafion ${ }^{\circledR}$ ionomer-similar to the composition successfully used in PEM fuel cells - is being tested. This electrode has a total catalyst loading that results in a reduction of more than $85 \%$ as compared to the baseline.

\footnotetext{
${ }^{2}$ Levene, J.; Ramsden, T. (January 2007). Summary of Electrolytic Hydrogen Production. Milestone Report. NREL/MP-560-41099. Golden, CO: National Renewable Energy Laboratory.
} 
All of the PEM electrolyzer companies consulted have developed systems that can produce hydrogen at a pressure of at least $300 \mathrm{psi}$ without the use of a gas compressor. This is done by either pressurizing the feed or using electrochemical compression within the electrolyzer. The companies have developed the necessary sealing technology to accommodate high-pressure operation.

Alkaline electrolyzer improvements are also being pursued. These developments typically target reduced capital costs by increasing pressure, reducing complexity, using novel materials, increasing current density, or performing a combination of these methods. Elevated pressures are achieved by either making the seals withstand pressure or surrounding the electrolyzer with a pressure vessel capable of reaching pressures greater than $400 \mathrm{psi}^{3}{ }^{3}$ Designs are tested both with balanced $\mathrm{H}_{2} / \mathrm{O}_{2}$ pressure and with a significant pressure difference across the membrane. Metal components - such as frames and supports - are being substituted with molded polymers or elastomers. Current densities are increased from a conventional level of $200 \mathrm{~mA} / \mathrm{cm}^{2}$ to approximately $1,000 \mathrm{~mA} / \mathrm{cm}^{2}$ by using new membranes and reducing gaps between electrodes.

One vendor, for example, describes a pressurized hydrogen generator module for large-scale applications designed to be compact, flexible, and efficient. Improved energy efficiency and a small footprint are achieved by operating at $300 \mathrm{psi}$, eliminating pumps by using self-circulation of the lye system, and performing integrated gas separation within the module. The use of separate electrolyte circulation on the anode side and cathode side enhances gas purity. Full-scale tests have shown that gas taken directly from the cell stack exhibits oxygen impurities of less than $0.6 \%$ and hydrogen impurities of less than $0.1 \%$.

\subsubsection{Capital Costs}

The direct capital cost of the hydrogen plant is one of the three most significant parameters in calculating the total cost of hydrogen from electrolysis - the other two being the cost of electricity and the electrolyzer efficiency. Information was gathered for both cost and efficiency from open sources and from interested suppliers. Suppliers' cost estimates were to be based on "state-of-the-art current technology" - the best technology that they have demonstrated, at least in the laboratory. The estimates therefore involve some extrapolation and scale-up to commercial electrolysis units, providing the suppliers with several challenges.

- Cost projections of the electrolyzer cell stack are based on limited experience and frequently on smaller cells and fewer cells per stack.

- Pricing experience for purchased components is based on lab- or pilot-scale procurement, thus requiring electrolyzer companies to work with vendors and extrapolate prices to greater volumes.

\footnotetext{
${ }^{3}$ In one extreme case, hydrogen pressures in excess of 5,000 psi were reported.
} 
- Limited experience of some suppliers/developers in designing, estimating, and purchasing balance-of-plant (BOP) equipment such as transformers, rectifiers, and control systems.

- Cost projections for developed markets were requested, specifically for 500 identical units per year for the forecourt design, and a repeat installation of "the ${ }^{\text {th }}$ plant" for the central case. The manufacturing methods and the supply chains needed for this scale have not been developed, and the expected cost reductions are not well understood.

Despite these challenges, suppliers were asked to provide cost estimates for purchased plants for forecourts and for the complete designed and installed (turnkey) central plant case by completing the Fact Sheet shown in Appendix A.

Most process plants have a non-linear relationship between the cost of the plant and its production capacity. This is known as the power law, and generally is expressed as follows.

$$
C=W^{n}
$$

Where $C$ is the capital cost of the plant (\$) and $W$ is the capacity (e.g., kilograms per day). The exponent $n$ typically has a value of between 0.6 and 0.8 , depending on the type of plant. This gives an economy of scale because costs increase less than proportionally as capacity is increased. Power law relationships generally hold up to a maximum value of $W$, which reflects the maximum practical size of the limiting process unit. For greater total capacities, parallel units must be installed and the cost relationship becomes linear or nearly so ( $n$ approaches 1$)$.

For electrolyzers the limiting unit is the cell stack itself. The area of each electrode is limited both by manufacturing and by fluid dynamics, and the number of cells in a stack is limited by tolerances in manufacturing and by the need to avoid excessive voltages across the stack. The largest commercial electrolyzer cell stacks today have a capacity on the order of $1,000 \mathrm{~kg}-\mathrm{H}_{2}$ per day. For greater capacities, several parallel cells stacks can be placed in one electrolyzer and/or several electrolyzers can be installed, with some sharing of utilities such as power electronics and controls and possibly other balance-of-plant components. As a first approximation, a power law cost relationship is expected to hold up to the capacity of the individual cell stack, and costs increase nearly linearly with capacities beyond this point. Sources in the industry have confirmed that a power law relationship with an exponent $n$ of between 0.6 and 0.7 seems to hold for a wide range of capacities in today's market - up to about $1,000 \mathrm{~kg} / \mathrm{day}$.

The aggregate vendor data do not validate the power law model for electrolyzer costs. In fact, there is no significant correlation between cell size or unit capacity and total cost in the Panel's data. Differences between vendor technologies seem to overshadow this effect, but it is reasonable to assume that within one technology a power law still holds. This implies that further developments could devise technologies that increase the largest available cell stack size, and thus the total capital cost could be reduced significantly.

Traditionally, PEM electrolyzers have targeted the smaller capacities, and alkaline systems have dominated the high-capacity industrial market. The PEM developers are striving towards larger cell sizes and larger stacks, but even in anticipation of this development most PEM suppliers hesitate to go beyond $500 \mathrm{~kg} /$ day per cell stack in their projections. Many base designs on cell 
stacks having a capacity of less than $250 \mathrm{~kg}-\mathrm{H}_{2} /$ day. Two suppliers of alkaline technology project a capacity of $1,500 \mathrm{~kg} /$ day in an individual cell stack, but this also is dependent on successful scale-up and demonstration of their technologies.

Consequently, the central case and, for some technologies, even the forecourt case involve installation of multiple electrolyzers in parallel. (A central plant with a capacity of 50,000 kg/day would have in excess of 50 cell stacks.) This gives a cost penalty compared to a situation in which the size of each unit is increased; suggesting that increasing the maximum unit size of each electrolyzer can be a cost reduction target in itself, particularly for large installations. Having multiple units in parallel also has benefits, however, as it allows for maintenance and unscheduled shutdowns of individual electrolyzer units and leaves the rest of the plant operational.

Balance-of-plant costs — dominated by items like transformers, rectifiers, and control systemcomprise a significant portion of the total installed costs. The BOP also includes water purification, hydrogen dryer, and a hydrogen purifier if needed. The estimated percentage varies considerably between suppliers (from $34 \%$ to $86 \%$ of the total cost excluding storage and dispensing), emphasizing the uncertainty in these estimates and for how each supplier draws the line between the electrolyzer and BOP. Most development work to reduce the cost of electrolysis focuses on the cost of the cell stack. Realizing that the BOP might cost as much, these items should receive attention as well.

Looking ahead at a developed market for the current state-of-the-art technology requires methods for estimating cost reductions as the number of units increases by orders of magnitude. Installation of 500 forecourt electrolyzer operations per year, each with a capacity of $1,500 \mathrm{~kg}$ of hydrogen per day, equals more than the current global industrial market for this size electrolyzer. Suppliers of small PEM electrolyzers probably are in the best position to estimate the effect of manufacturing a great number of identical units, but they must extrapolate to considerably greater unit capacities than those with which they are experienced. Conversely, suppliers of alkaline units have capacities that are closer to those needed but have limited experience with high-volume manufacturing. In both cases the cost projections are uncertain. The consensus seems to be that a developed market will see unit costs coming down by a factor of two or more as compared with low-volume manufacturing. New manufacturing methods and new supply chains should be studied to verify that this cost reduction is achievable. In the Panel's view, such reductions remain a realistic assumption. Drawing on mass manufacturing developments for fuel cells also can contribute to reduced unit costs for electrolyzers.

As long as the maximum capacity of individual electrolyzer cell stacks is less than or equal to the capacity needed for the forecourt case $(1,500 \mathrm{~kg} /$ day $)$, the total installed cost per unit capacity will be roughly the same for both the forecourt and central production cases, excluding other capital considerations such as buildings, compression, storage, and dispensing costs. A forecourt refueling station will be based on containerized prefabricated units and the central plant will have a more open layout; there also will be other differences in the scope.

Figure 2 shows the range of capital costs (obtained from electrolyzer companies) as a function of capacity. There is no relationship between capital cost and capacity due to the variety of technologies represented and perhaps differences in capability and approaches used to project costs to the large market volumes requested (as discussed above). Within the uncertainty of the 
collected information, however, the Panel thinks a fair number to be used for the purchased capital cost is $\$ 800$ per kilogram per day of capacity (in 2005 reference year dollars ${ }^{4}$ ) giving a total purchased cost of $\$ 1.2$ million (in 2005 reference year dollars) for the forecourt case. The central case is based on estimating the total depreciable costs (turnkey) which-with roughly the same purchased cost for the electrolyzer units - is found to be $\$ 50$ million (in 2005 reference year dollars). Both estimates assume that the capacity of each electrolyzer unit will not exceed $1,000 \mathrm{~kg} / \mathrm{day}$.

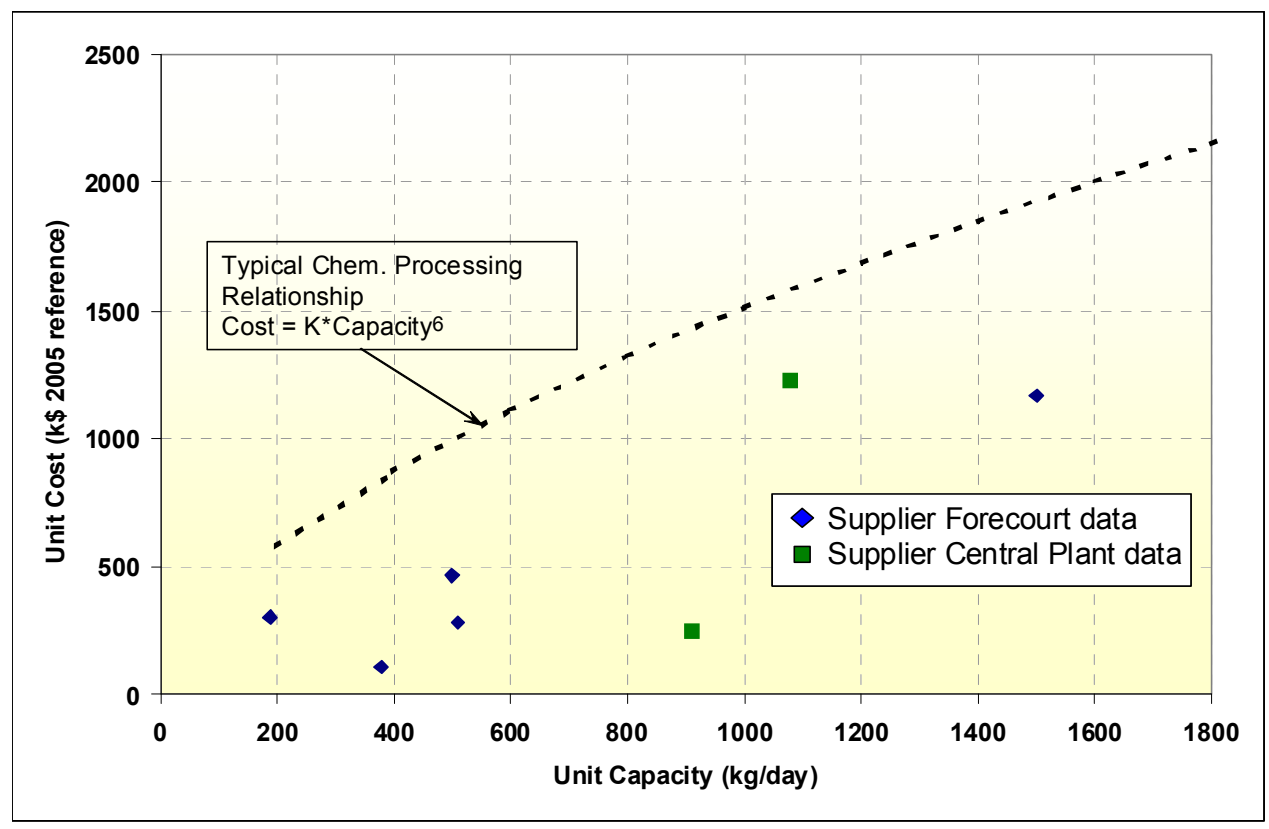

Figure 2. Vendor capital cost information (in 2005 reference year dollars ${ }^{4}$ )

The spread in cost data from the suppliers is considerable, with unit costs varying from $\$ 370$ to $\$ 1,600$ per kilogram per day. Part of the discrepancy can be explained by differences in technology and high-volume projection approaches, but it also is thought that the degree to which the vendors have anticipated successful new development in technology, design, and manufacturing varies. Overall, the data given by suppliers is considered to have an optimistic bias when seen as estimates for state-of-the-art technologies and those that could be commercial within four years. The base-case cost estimates reflect this, as they are greater than the mean of the data from the suppliers.

The choice of capital cost to be used as input in the H2A model does not imply a specific technology or vendor. Even the choice between PEM and alkaline remains open, as our numbers indicate that PEM could have the potential for reduced cell stack costs but using somewhat smaller unit capacities than those of the alkaline technologies. Within the margin of error, these effects compensate for one another.

\footnotetext{
${ }^{4}$ The DOE Hydrogen Program expresses cost information in 2005 reference-year dollars and asked the Panel to do the same. The Panel converted the cost information it received (in 2008 dollars) to 2005 dollars using EIA data. See Section 5.3. One vendor data point at a unit cost of $\$ 4,000,000(\mathrm{k} \$ 4000)$ is not shown on the graph.
} 


\subsubsection{Electricity Costs}

Our analysis finds that electricity costs are a major contributor to the overall cost of hydrogen. As is shown in Section 5.3, electricity accounts for nearly $80 \%$ of the cost of hydrogen from electrolysis using current state-of-the-art technology. An initial cost boundary analysis was completed to determine the effect of electricity price on hydrogen costs. For the range of electrolyzers studied, the specific system energy requirement (see Section 5.3) was used to determine the electricity cost to produce hydrogen as a function of the price of the electricity and is shown in Figure 3. A line showing the theoretical electricity cost at 100\% (HHV) efficiency also is included in the figure. No capital, operations and maintenance (O\&M), or other costs are included in the calculation. As shown in Figure 3, at current (2009) state-of-the-art electrolyzer efficiencies, the electricity cost of producing hydrogen is $\$ 2 / \mathrm{kg}$ to $\$ 3 / \mathrm{kg}$ at typical industrial electricity prices of $\$ 0.04 / \mathrm{kWh}$ to $\$ 0.06 / \mathrm{kWh}$. This can be compared to the overall DOE Hydrogen Program long-term goal of delivered hydrogen costing $\$ 2 / \mathrm{kg}$ to $\$ 3 / \mathrm{kg}$. The delivered cost includes not only all the other production cost contributions (e.g., capital, O\&M) but also the cost of hydrogen delivery. For the case of forecourt operations this includes the refueling station operations of compression, storage, and dispensing. For central production it includes these refueling site costs plus the cost to transport the hydrogen from the central plant to the refueling station.

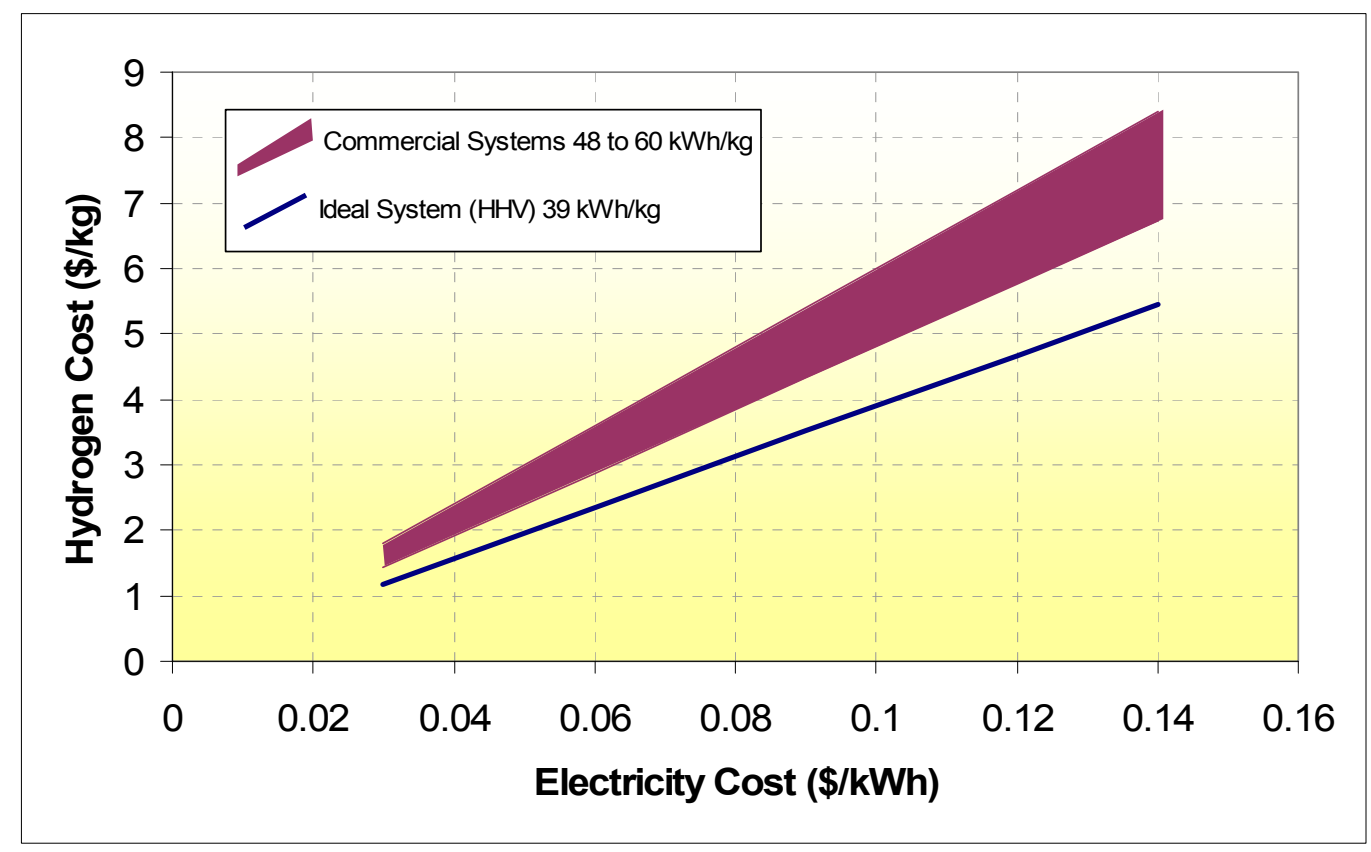

Figure 3. Influence of electricity cost alone on hydrogen cost (without capital, operating, or maintenance costs)

The electricity consumption of a forecourt or central production installation should be eligible for industrial electricity rates due to the amount of electricity consumed. Data from Energy Information Administration (EIA) shows a great variation among U.S. states in wholesale and retail electric costs for the commercial, industrial, and transportation sectors. Figure 3 shows the state-by-state variation for the industrial sector for the year 2007. The data shows that the industrial price for electricity varies from a low of $\$ 0.0387$ per kilowatt-hour in Idaho to a high 
of $\$ 0.1838$ per kilowatt-hour in Hawaii. Figure 4 shows EIA data on the average and spread of data in the United States for the years 1990 through 2008. For electrolysis to be priced competitively for hydrogen production, it must be produced in areas having low-priced electricity for the industrial sector. The U.S. average price is $\$ 0.0639 / \mathrm{kWh}$.

One additional approach that should be considered to reduce electricity cost is the use of interruptible power. The local utility establishes the minimum demand level, notification time, and interruption duration for the service, and qualifying customers could see a $10 \%$ to $30 \%$ reduction in the price of electricity. To minimize the impact of a power interruption, the outage duration and frequency should be evaluated against the cost of the potential reduction in production capacity and the increase in storage required to meet hydrogen demand needs. One striking advantage of electrolysis hydrogen production is its ability to essentially instantaneously decrease, stop, and increase production rates compared with much more slowly responding thermochemical production options. This makes electrolysis particularly well suited to try to take advantage of interruptible power rates.

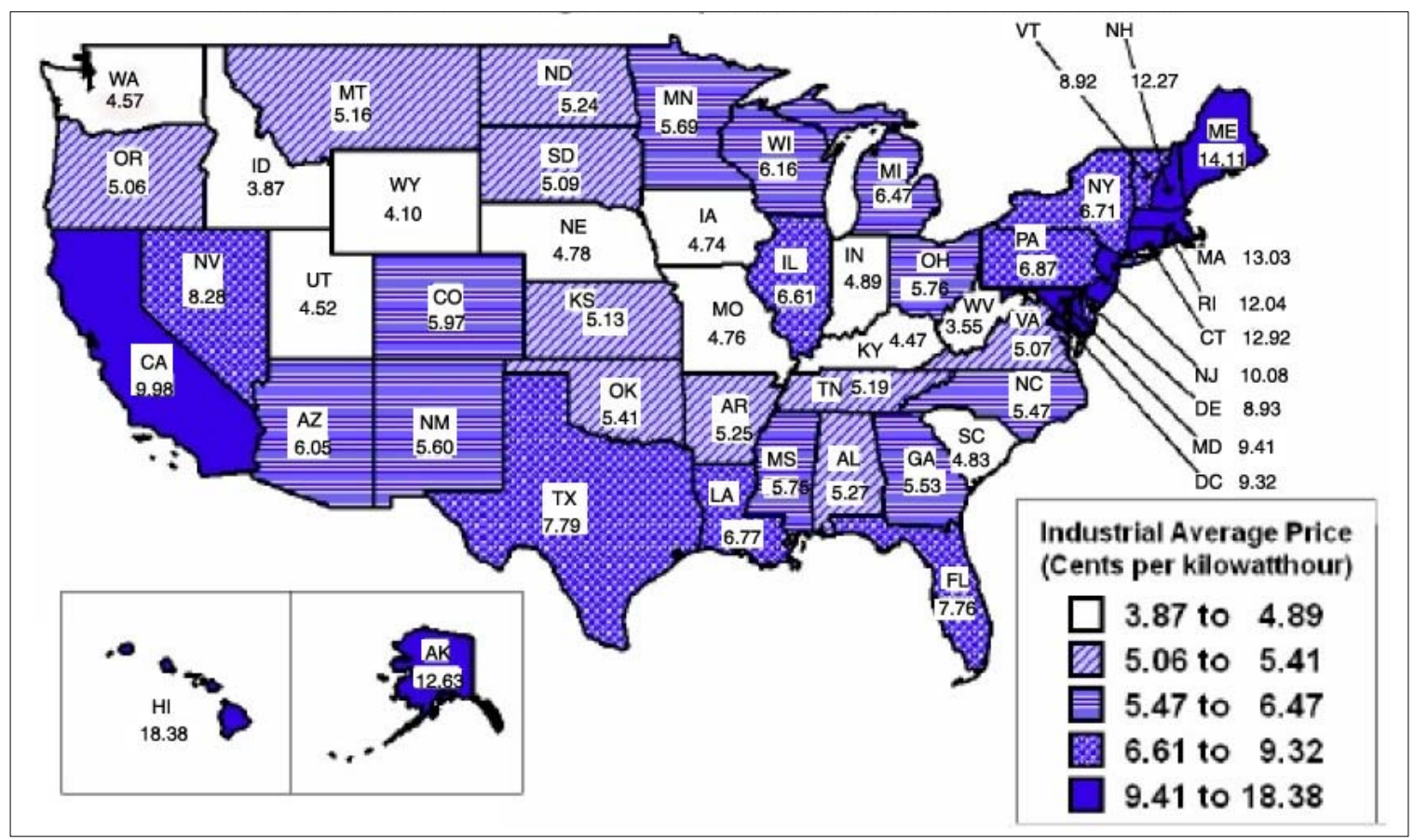

Figure 4. Average industrial price for electricity by state ${ }^{5}$

For the purposes of this assessment, the Panel was instructed by DOE to use the price of electricity for the forecourt projected by the EIA AEO 2005 High A case from 2005 through 2025 . This average is $\$ 0.053 / \mathrm{kWh}$. For the central electrolysis case DOE provided a cost of $\$ 0.045 / \mathrm{kWh}$ based on renewable electricity. See Section 5.3 for more details.

\footnotetext{
${ }^{5}$ Energy Information Administration (January 2009). Electric Power Annual with Data for 2007. Figure 7.7. http://www.eia.doe.gov/cneaf/electricity/epa/epa_sum.html. Accessed September 21, 2009.
} 


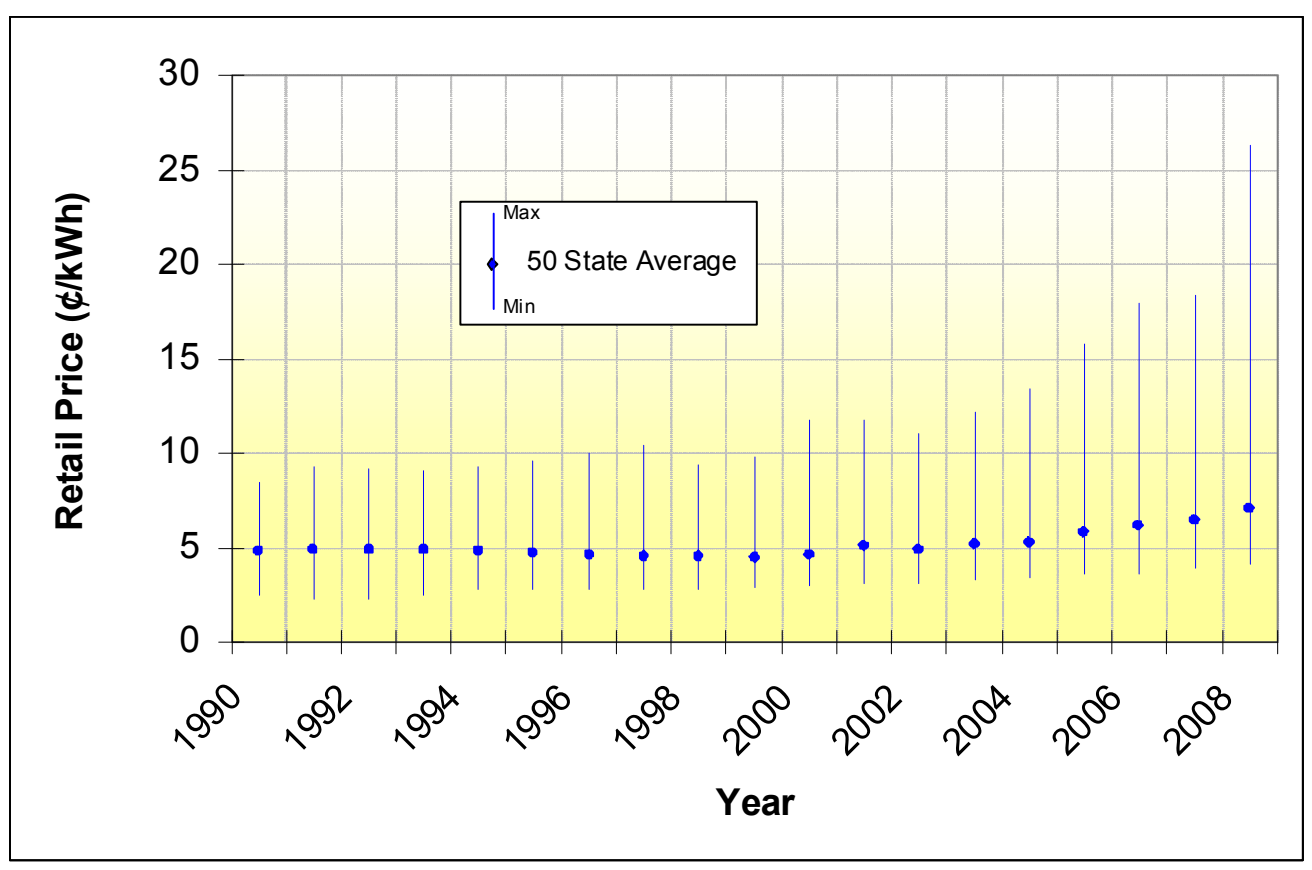

Figure 5. Historical variation in the average retail rate for the industrial sector

\subsubsection{Energy Efficiency}

Based on information provided by electrolyzer suppliers for their state-of-the art technologies, both alkaline and PEM electrolyzers are now capable of producing hydrogen using less than 50 $\mathrm{kWh} / \mathrm{kg}$, representing a lower heating value efficiency of greater than $67 \%$ (see below for a detailed discussion of lower heating value versus higher heating value efficiency). Note that this refers to the complete electrolysis operation and includes the power electronics and other balance of plant components (e.g. dryer). The efficiency of the electrolyzer stack is higher, with cell efficiencies as high as $74 \%$ LHV. These efficiency gains reflect development work of both PEM and alkaline electrolyzer suppliers to reduce the energy consumption of the electrolyzers.

Reduced membrane thickness and more compact cell designs reduce ohmic losses, more efficient catalysts and improved hydrodynamics at the electrode surface reduce over-voltages on both anodes and cathodes.

It is not likely, however, that the PEM and alkaline technologies evaluated here will achieve significantly greater cell efficiencies. The technologies are at the point of diminishing returns on efficiency, and the scope for further improvement is likely to be more focused on further capital cost reduction, reliability and durability, and the scale-up to greater capacities. A shift in technology platform however - for instance by introducing high temperature electrolysis - could increase the expected efficiencies. All the technologies evaluated for this report operate at conventional temperatures of between $70^{\circ} \mathrm{C}$ and $85^{\circ} \mathrm{C}$, and use only electric energy to drive the process.

The total energy spent to produce hydrogen exceeds that of the electrolyzer stack. The balance of plant has ohmic and thermal losses in power electronics, pumps, and auxiliaries. For some technologies there also can be a loss of hydrogen through purging and venting which reduce the net efficiency of usable hydrogen production. The energy use outside the electrolyzer represents 
an additional $5 \%$ to $10 \%$ loss. Some further improvement in these parasitic losses might be possible. Such losses could be significantly greater if compression is needed to reach the 300 psig pressure specified at the electrolysis plant outlet. Most technologies under development operate the electrolysis at this pressure or at greater pressures, eliminating the need for a firststage compression to $300 \mathrm{psig}$. Compression for storage and dispensing is handled separately.

To better understand electrolyzer efficiencies as reported, it is important to recognize the differences between lower heating value (LHV) and higher heating value (HHV) efficiency. According to Faraday's law, the amount of chemical change during electrolysis is proportional to the charge passed. In other words, the current passing through an electrolysis cell defines the rate of hydrogen (and oxygen) being produced. This relationship also holds true for commercial electrolyzers because leakage currents between cells normally are negligible. In numerical terms, the rate of production per cell is as follows.

$$
W_{v}=0.41 * I
$$

Where $W_{v}$ is the volumetric rate of production of hydrogen $\left(\mathrm{Nm}^{3} / \mathrm{h}\right)$ and $I$ is the current through the cell (kA). In mass-flow terms, this becomes the following.

$$
W=0.89 * I
$$

Where $W$ is the rate of production of hydrogen in kilograms per day.

The theoretical total energy needed to split the water molecule is defined by the heat of reaction, which is the reverse of the heat of combustion (heating value) of hydrogen. Values conventionally are given as either HHV or LHV, based on the end-product of combustion being either liquid water or water vapor. ${ }^{6}$ Using units that are useful for this exercise, the heating values for hydrogen are HHV: $39.42 \mathrm{kWh} / \mathrm{kg}$ and LHV: $33.31 \mathrm{kWh} / \mathrm{kg}$. Most practical electrolyzers use liquid water as feed, making it reasonable to refer energy efficiencies to the higher heating value. It is conventional, however, to refer to LHV for efficiencies of both electrolyzers and fuel cells; $100 \%$ HHV efficiency $\left(\eta_{H}=100 \%\right)$ translates into $84.5 \%$ efficiency based on LHV $\left(\eta_{L}=84.5 \%\right)$.

The electric energy consumption in electrolysis is directly proportional to the cell voltage that must be applied, because current and mass flow are directly proportional and power equals current times voltage. The minimum reversible voltage is $1.23 \mathrm{~V}$, equivalent to the change in Gibb's free energy for the reaction. This reflects the minimum amount of energy that must be applied as electricity; the total energy is greater. A more realistic number is $1.48 \mathrm{~V}$, the voltage required at $\eta_{\mathrm{H}}=100 \%\left(\eta_{\mathrm{L}}=84.5 \%\right)$. This is known as the thermoneutral voltage, and it represents a $100 \%$ electric energy efficient electrolyzer that has electricity as its only energy input. An electrolyzer with a lower voltage (i.e., $\eta_{L}>84.5 \%$ ) requires some of its energy input from non-electric sources, such as thermal energy. This is relevant mostly for future high temperature electrolyzer technologies.

\footnotetext{
${ }^{6}$ The heating value definitions also vary with respect to the end temperature of the combustion products.
} 


\subsubsection{Working Capital}

For most process plants, working capital is predominantly the storage of raw materials and products. In the case of the central electrolysis plant this part of working capital is not relevant. Electricity and water - the raw materials - are used on demand. The hydrogen product is assumed to be exported through a pipeline on a continuous basis, as discussed above.

Working capital is needed for purchasing spare parts for critical components, however. Specifically, one or two complete electrolyzer units should be available to achieve the high availabilities assumed in Section 4.3.1, and key parts or complete spares of non-duplicated critical units should be stored on-site. Working capital commonly is defined in terms of the change in percentage of the annual operating cost. The Panel, using this definition, has set the expected working capital (somewhat arbitrarily) at 5\%-considering this to be adequate for any reasonable O\&M strategy for a central plant. For the forecourt case the working capital was set even lower, at $1 \%$ of annual operating cost. In this case, a shared maintenance program that serves a great number of stations is expected, so each station has little need for working capital.

This is in contrast to other DOE published H2A hydrogen production cases which use $15 \%$ for working capital. Most of these DOE cases are for thermochemical processes that require significant working capital for raw material storage and more spare parts for these more complex processing operations. The DOE H2A forecourt and central electrolysis cases also adopted the $15 \%$ working capital figure. The sensitivity analysis in Section 5.4 shows that the hydrogen cost is not sensitive to these working capital assumptions.

\subsection{Forecourt Electrolysis}

\subsubsection{Capacity Factor and Storage}

The primary cost drivers for electrolysis are capital cost, electricity price, and electrolysis efficiency. The capacity factor of the electrolysis production unit, however, can impact the delivered cost of hydrogen at a forecourt refueling station. Although the Panel was not asked to review the refueling station compression, storage, and dispenser elements $(\mathrm{C} / \mathrm{S} / \mathrm{D})$, it knew that the production unit capacity factor was dependent on the amount of storage available. The Panel called upon two recognized experts - Amgad Elgowainy (Argonne National Laboratory) and Brian James (Directed Technologies Inc.) - to help the Panel understand this interaction and the basis for the capacity factor used in the published H2A forecourt electrolysis case. The latest H2A Forecourt Production Model (version 2) is based on the work conducted in this area by Elgowainy and James. Based on these discussions, the Panel felt that the methodology used in the H2A Forecourt Production Model might more appropriately be revised based on the capabilities of electrolyzer production technologies. A description of this revised approach is provided in Appendix B, in a white paper co-authored by Elgowainy and James.

Based on Appendix B, the key parameters that determine the forecourt production unit capacity factor (and the station low-pressure storage needs) are shown in Table 2 (below). The table shows the values used for these parameters in the DOE published H2A Current Forecourt Hydrogen Production from Grid Electrolysis (1,500 kg/day) version 2.1.2, which was the starting point for this Panel (see Section 5.2), as well as the values that the Panel thinks are most appropriate to represent current (2009) state-of-the-art forecourt electrolysis technology. 
Table 2. Key Parameters for the Forecourt Production Unit Capacity Factor

\begin{tabular}{|c|c|c|c|c|}
\hline \multicolumn{2}{|l|}{ Parameter } & Units & $\begin{array}{c}\text { Current H2A } \\
\text { Electrolysis Case }\end{array}$ & $\begin{array}{c}\text { Panel } \\
\text { Consensus }\end{array}$ \\
\hline \multirow{2}{*}{ Summer Peak Demand } & Duration & Days & 120 & 120 \\
\hline & Excess Demand & $\%$ Greater than Average & 10 & 10 \\
\hline \multirow{2}{*}{ Winter Low Demand } & Duration & Days & 120 & 120 \\
\hline & Reduced Demand & $\%$ Less than Average & 10 & 10 \\
\hline Weekday Peak Demand & Excess Demand & $\%$ Greater than Average & 13 & 13 \\
\hline Scheduled Annual Maintenance & Duration & Days & 14 & 5 \\
\hline \multirow{2}{*}{ Unscheduled Maintenance } & Frequency & \#/Year & 6 & 4 \\
\hline & Duration & Hours & 14 & 14 \\
\hline $\begin{array}{l}\text { Minimum Time } \\
\text { Between Occurrences }\end{array}$ & Interval & Days & 30 & 30 \\
\hline
\end{tabular}

The first five parameters in Table 2 relate to data collected by the DOE H2A Hydrogen Delivery effort and were left unchanged. The last four variables were discussed by the Panel both internally and with various electrolyzer vendors. One of the advantages of electrolysis is that there are very few moving parts and the operations occur under relatively mild conditions. Based on discussions with vendors, the Panel has set the scheduled annual maintenance at 5 days and split into one 3-day event and one 2-day event. Unscheduled maintenance is expected to be rare, but the Panel agreed on 4 times per year, 14 hour duration, and a minimum time of 30 days between the events. The 14 hour duration is to provide sufficient time for any necessary parts to arrive at the site and be installed, as is assumed in all the published H2A forecourt cases.

Using these parameters and the equations in Appendix B, the calculated operating capacity is $87.8 \%$ - compared with $85.2 \%$ in the DOE published H2A Current Forecourt Hydrogen Production from Grid Electrolysis $(1,500 \mathrm{~kg} /$ day) version 2.1.2. This increase in the production capacity factor reduces the hydrogen delivered cost by about $\$ 0.06$ per kilogram. The equations in Appendix B also calculate the amount of usable low-pressure storage required at the station as $1,500 \mathrm{~kg} \mathrm{H}_{2}$ versus the $1,380 \mathrm{~kg}$ of $\mathrm{H}_{2}$ in the DOE published forecourt case (1,500 kg/day). This results in an increase in the delivered cost of hydrogen of about $\$ 0.12$ per kilogram. Thus, the change of the parameters as indicated in Table 2 results in a net increase in the delivered cost of hydrogen of about $\$ 0.06$ per kilogram. The Panel believes this to be the more appropriate method for calculating forecourt production capacity factors and storage needs. The actual result will depend on the assumed values of input parameters.

\subsubsection{Power Services Capital Costs}

The typical $3 \mathrm{MW}$ forecourt electrolyzer system requires a capital expenditure to cover the cost of electrical installation and connection to the electric grid. These costs can include electrical system upgrades, transformers, and trenching. Based on its discussions with utility sector experts, the Panel learned that utilities typically provide some sort of line extension policy for large commercial customers to help defray the capital costs associated with electrical installation and hookup. In some cases, utilities require some level of customer "contributions in aid" of construction and installation, typically $10 \%$ to $20 \%$ of the costs incurred. In these instances, a typical $3 \mathrm{MW}$ forecourt facility could require a customer contribution in aid of between $\$ 50,000$ 
and $\$ 100,000$. Many other utilities provide new customers with a construction credit allowance to cover the cost of electrical hookups. A new $3 \mathrm{MW}$ commercial load might be provided a construction credit allowance of between $\$ 500,000$ and $\$ 1$ million-which is more than adequate to cover typical electrical installation costs for a forecourt facility.

In the Panel's cost analysis of forecourt production, no additional capital costs were included for electrical installation, based on an assumption that utility construction credit allowances would cover these costs (and the installation costs would be subsumed under the per kilowatt-hour rate charges). For installations in areas served by utilities that require customer contributions in aid, the additional expected additional installation costs would not appreciably affect the resulting cost of hydrogen production.

\subsubsection{Cooling}

Electrolyzers require cooling. For a typical $3 \mathrm{MW}$ forecourt installation with a LHV energy efficiency of $67 \%$, roughly $1 \mathrm{MW}$ of cooling is required, using approximately $390 \mathrm{gpm}$ of cooling water. ${ }^{7}$ The cost for cooling water does not contribute significantly to the total cost of hydrogen, but in some locations the availability of water can be limited. In such cases, an air cooler could be supplied with the electrolyzer, reducing the cooling water consumption but increasing the capital costs slightly. These variations are within the margin of error in calculating hydrogen costs. The Panel used cooling water in its estimates.

\subsection{Central Production}

\subsubsection{Capacity Factor (Central Plant)}

The plant capacity factor is the net production per year divided by the theoretical output capacity of the plant. For a central plant, three factors can reduce the capacity factor:

- Insufficient or no power available for production;

- Partial or total shutdown of the hydrogen production plant, including electrolyzers; and

- Limited demand for hydrogen, requiring plant operation at reduced capacity.

Based on input from vendors and its own experience, the Panel estimated that a mature design ("the $\mathrm{n}^{\text {th }}$ plant") should be able to see a capacity factor of $98 \%$ for the hydrogen plant itself. This only is an estimate, because such plants have not been built for decades and none of the suppliers has designed such a complete plant. Additionally, the demand side has not been considered in this evaluation of the capacity factor. The assumption is that a pipeline or other suitable delivery option with buffer storage always is available to take off the hydrogen being produced.

In the definition for the central case, the basic assumption is that the electrolysis plant is connected to a grid supplying renewable power - this assumes that the grid is stable and reliable, and neglects any unavailability of power. If an electricity contract for "interruptible power" at reduced rates is introduced (see Section 4.1.3), then a forced shutdown must be expected at some interval, thus reducing the capacity factor. Such interruptible power has not been taken into

\footnotetext{
${ }^{7}$ Once-through cooling water with a temperature increase of $10^{\circ} \mathrm{C}$, ignoring ambient heat losses.
} 
account in the present evaluations; if it were, then the frequency and duration of contract-based outages would require evaluation for specific cases.

A standalone wind hydrogen plant has a very different capacity factor. Variability of power generated from the wind turbines translates directly into a reduced capacity factor for the hydrogen plant, unless the installed power of the turbines is much greater than that of the electrolyzers. Capacity factors for current large wind farms can be as low as $40 \%$.

For a central plant with a great number of parallel electrolyzer units (50 or more; see Section 4.1.2), planned and unscheduled maintenance of the electrolyzers both reduce the output of the plant by only one-fiftieth during the partial shutdown. Taking out each of the units for one week per year on a rotational basis, for example, reduces the overall capacity factor by $2 \%$. Even this is a more frequent repair than should be expected. Total shutdown only occurs if one of the non-parallel units fails. Examples include control and safety systems, compressors, and cooling water supply. Sound design engineering should include a mean time of several years between failures for such systems.

In evaluating capacity factors for electrolyzers it is important to recognize that they often can restart immediately following a brief loss of power, and they also respond very quickly to variable supply (power) or demand by increasing or decreasing production. Both the characteristics of the individual electrolyzer unit and the multi-parallel design provide a flexibility which makes very high capacity factors realistic.

\subsubsection{Land Costs}

The H2A published central production cases use a land cost of $\$ 5,000$ per acre. More recently, however, DOE had Directed Technologies, Inc. (DTI) conduct research in this area. Based on DTI's research, $\$ 50,000$ per acre is a more suitable value for an average land cost for a central production plant located at or beyond the edge of a U.S. city. This value was adopted in the H2A Delivery Model, version 2, ${ }^{8}$ and the Panel also elected to use it. Land is such a small part of the cost of hydrogen from a central electrolysis plant that the change had no impact on the cost of the hydrogen produced.

\subsubsection{Power Services Capital Costs}

Based on the instructions from the DOE Hydrogen Program, it was assumed that the central electrolysis plant received renewable based electricity from some source. The Panel discussed whether the cost of the electrolysis plant should include some capital cost for power lines and other electrical servicing equipment, and decided not to include such costs. Renewable wind, solar, geothermal, and hydroelectric electricity plants only will be located in the areas of the country where those resources are available. It could be very costly to run power lines from these renewable electricity plants to electrolysis plants unless the electrolysis plants were co-located or located very near the renewable electricity plants. The Panel thinks this should be a consideration when analyzing the cost of hydrogen produced from central electrolysis plants based on renewable electricity. Based on limited discussions with utility companies, these capital costs might be absorbed by the utility companies but the cost would be reflected in the electricity price.

\footnotetext{
${ }^{8}$ Http://www.hydrogen.energy.gov/h2a analysis.html. Accessed September 19, 2009.
} 


\subsubsection{Buildings Capital Costs}

As discussed in Section 4.1.2, it is challenging for an electrolyzer company to estimate the all in capital costs for a large central electrolysis plant. These companies are in the business of selling electrolyzer units and not in the business of designing and constructing complete turnkey central plants. The Panel noticed, for example, that none of the vendors specifically mentioned buildings in their estimates. Therefore a capital cost of $\$ 3$ million for buildings was added to the estimates the Panel received. This was based on examination of other DOE published H2A central plant cases, such as for biomass gasification and coal gasification. The $\$ 3$ million is somewhat less than the building costs used for the thermochemical plants because those plants are larger and more complex.

\subsubsection{Cooling Costs}

In the large-scale central case - requiring $100 \mathrm{MW}$ of electric power input - the cooling water consumption is proportionally more than that of the forecourt installation. For once-through cooling, more than 10,000 gpm (15 million to 20 million gallons per day) of water ${ }^{9}$ is needed. In this case, evaporative cooling using a cooling tower often is preferable. This reduces the water consumption by a factor of about 50 and increases direct capital cost. The Panel's calculations are based on once-through cooling and typical costs for industrial water, but other more realistic scenarios would have a similar, and limited, impact on the final costs.

\section{Panel H2A Modeling Analysis}

\subsection{H2A Model Introduction}

The DOE Hydrogen Analysis (H2A) effort was organized to develop the building blocks and framework needed to conduct consistent and transparent cost, energy efficiency, and greenhouse gas (GHG) analyses of hydrogen production and delivery over a wide range of hydrogen technologies. Initiated in fiscal year 2003, the H2A effort has brought together the analysis expertise in the hydrogen community, drawing from industry, academia, and the national laboratories. There currently are four H2A Excel-based models for hydrogen technology analysis.

- H2A Distributed Forecourt Production and Refueling Model $(50 \mathrm{~kg} /$ day to $6,000 \mathrm{~kg} /$ day production)

- H2A Central Production Model ( $\geq 50,000 \mathrm{~kg} /$ day production)

- H2A Delivery Components Model

- H2A Delivery Scenario Analysis Model (HDSAM)

In addition to the models, DOE contracted analysis experts to develop production and delivery cases for various production technologies and delivery pathways. The models and cases have been vetted by appropriate industry experts and other experts on hydrogen technologies and costs. Both of the H2A models and cases can be found at http://www.hydrogen.energy.gov/ h2a_analysis.html.

\footnotetext{
${ }^{9}$ Once-through cooling water with a temperature increase of $10^{\circ} \mathrm{C}$.
} 


\subsection{H2A Modeling Analyses Provided}

All of the DOE H2A cases were available to the Panel through DOE's H2A website. Most pertinent were the two current cases on hydrogen production utilizing electrolysis:

- Current Forecourt Hydrogen Production from Grid Electrolysis (1,500 kg/day) version 2.1.2; and

- Current Central Hydrogen Production from Grid Electrolysis version 2.1.1.

It is the Panel's understanding that these analyses are meant to roughly characterize 2005 electrolysis technology, based on when these analyses first were generated. The Panel's data gathering efforts tended to confirm the validity of the capital costs and electrolysis operating efficiencies in these H2A model analyses for 2005 technology.

\subsection{Panel Baseline H2A Modeling Analysis}

The Panel was asked by DOE to express results in 2005 reference year dollars. The cost information obtained was presumed to be in 2008 dollars. To convert these to 2005 dollars to account for inflation, a factor of 0.922 was used. This deflation was based on information supplied by DOE from the most recent EIA AEO. All dollar figures in this report are expressed in 2005 dollars.

\subsubsection{Distributed Forecourt Production Base Case}

The Panel determined that, since 2005, there has been significant technology advancement in PEM and alkaline electrolysis which is applicable to distributed forecourt hydrogen production as represented in the estimated cost reduction presented below (and discussed in Section 4.1.1). The net change in hydrogen cost between the DOE published H2A Case for 2005 technology and the Panel's base case for current (2009) state-of-the-art technology is a reduction of $\$ 0.86 / \mathrm{kg}$ of hydrogen (see Table 3).

The starting point for the Panel's analysis was the H2A Current Forecourt Hydrogen Production from Grid Electrolysis (1,500 kg per day) version 2.1.2. All of the input parameters used in this case were examined and compared with all the information that was gathered as well as Panel members' own knowledge and experience. The parameters were modified as appropriate to represent the Panel's conclusions for state-of-the-art 2009 electrolysis technology to establish a base case.

Many of the H2A model input parameters were left unchanged, as deemed appropriate. This included all of the standard "H2A Default Values" for financial inputs and fixed and operating costs, with the one exception of working capital (discussed in Section 4.1.5). Also included were many other inputs, such as parameters concerning construction time and start-up, indirect capital costs, most of the fixed operating costs, and some of the other variable costs. No refueling station compression, storage, and dispensing $(\mathrm{C} / \mathrm{S} / \mathrm{D})$ inputs were changed, with the exception of adjusting the low-pressure storage amount (as discussed in Section 4.2.1).

The inputs that were changed are shown in Table 3. This table also shows the range of the values for these inputs that were provided by the participating electrolyzer companies, the values from the H2A Current Forecourt Hydrogen Production from Grid Electrolysis (1,500 kg per day) version 2.1.2 (H2A Case) meant to represent 2005 technology, and the Panel's base-case values. 
Also shown is the stepwise and cumulative change in the hydrogen cost, starting with the $\mathrm{H} 2 \mathrm{~A}$ Case.

Table 3. Panel Forecourt Production Base Case

\begin{tabular}{|c|c|c|c|c|c|c|c|}
\hline Forecourt & Vendor Range & Panel Base Case & H2A Case & $\begin{array}{c}\mathrm{H} 2 \text { Cost }(\$ / \mathrm{kg}) \\
\text { Production }\end{array}$ & $\begin{array}{c}H 2 \operatorname{Cost}(\$ / \mathrm{kg}) \\
\mathrm{C} / \mathrm{S} / \mathrm{D}\end{array}$ & $\left|\begin{array}{c}\mathrm{H} 2 \operatorname{Cost}(\mathbf{\$} / \mathrm{kg}) \\
\text { Total }\end{array}\right|$ & $\begin{array}{c}\text { Delta Total } \\
\text { Cost (H2A- } \\
\text { Panel) }\end{array}$ \\
\hline \multicolumn{4}{|l|}{ Current (2005) H2A Case } & $\$ 4.23$ & $\$ 1.82$ & $\$ 6.05$ & \\
\hline Production Purchased Capital Cost (M\$̦) & $\$ 0.57$ to $\$ 1.4$ & $\$ 1.20$ & $\$ 2.26 \mathrm{M}$ & $\$ 3.65$ & $\$ 1.79$ & $\$ 5.44$ & $\mid \$ 0.61)$ \\
\hline Total Energy (kWh/kg) & $48-59$ & 50.0 & 53.4 & $\$ 3.46$ & $\$ 1.79$ & $\$ 5.25$ & $(\$ 0.19)$ \\
\hline Electricity Price & $\mathrm{NA}$ & $\$ .055 / \mathrm{kWh}$ ElA & $\$ .055 / \mathrm{kWh}$ ElA & $\$ 3.46$ & $\$ 1.79$ & $\$ 5.25$ & $\$ 0.00$ \\
\hline Production Maintenance (\% of Purchased Capital) & $0.02 \%$ to $2.6 \%$ & $\$ 0.02$ & $\$ 0.06$ & $\$ 3.37$ & $\$ 1.79$ & $\$ 5.16$ & $(\$ 0.09)$ \\
\hline $\begin{array}{l}\text { Electrolyzer Cells Capital Replacement (k\$) } \\
\text { (\% of Total Production Purchased Capital) }\end{array}$ & $\begin{array}{l}\$ 38 \text { to } \$ 600 \\
7 \% \text { to } 45 \%\end{array}$ & $\begin{array}{l}\$ 420 \\
35 \%\end{array}$ & $\begin{array}{l}\$ 744 \\
33 \%\end{array}$ & $\$ 3.37$ & $\$ 1.79$ & $\$ 5.16$ & $\$ 0.00$ \\
\hline Eletrolyzer Cell Replacement Interval (yr) & 7 to 10 & 7 & 10 & $\$ 3.42$ & $\$ 1.79$ & $\$ 5.21$ & $\$ 0.05$ \\
\hline Op. Capacity Factor & NA & $88 \%$ & $85 \%$ & $\$ 3.40$ & $\$ 1.75$ & $\$ 5.15$ & $(\$ 0.06)$ \\
\hline C/S/D LP Storage (kg) & NA & 1691.00 & 1424.00 & $\$ 3.40$ & $\$ 1.87$ & $\$ 5.27$ & $\$ 0.12$ \\
\hline Working Capital (\% of Change in Operating Costs) & NA & $1 \%$ & $15 \%$ & $\$ 3.33$ & $\$ 1.87$ & $\$ 5.20$ & $(\$ 0.07)$ \\
\hline C/S/D Electrical Upgrade Installed Capital Cost (k\$) & NA & $\$ 0.00$ & $\$ 76.7$ & $\$ 3.33$ & $\$ 1.87$ & $\$ 5.20$ & $\$ 0.00$ \\
\hline Process Water (gal/kg-H2) & 2.3 to 2.9 & 2.50 & 2.94 & $\$ 3.33$ & $\$ 1.87$ & $\$ 5.20$ & $\$ 0.00$ \\
\hline Cooling Water (gal/kg-H2) & 0.1 to 290 & 290.00 & 0.10 & $\$ 3.36$ & $\$ 1.87$ & $\$ 5.23$ & $\$ 0.03$ \\
\hline All other Variable Costs (k\$/yr) & NG & $\$ 0.00$ & $\$ 19.40$ & $\$ 3.32$ & $\$ 1.87$ & $\$ 5.19$ & $(\$ 0.04)$ \\
\hline \multicolumn{4}{|l|}{ Total Cumulative Change } & $(\$ 0.91)$ & $\$ 0.05$ & $(\$ 0.86)$ & \\
\hline
\end{tabular}

Table 4 shows that the changes the Panel made that had the most significant impact on the hydrogen cost were production capital cost and energy use. These two variables plus the electricity price dominate the cost of hydrogen production from electrolysis. The rationale for the Panel's choices of parameters for its base case is discussed below.

- The basis for the production purchased capital cost and total energy use is discussed at length in Section 4.1.2 and Section 4.1.4, respectively.

- The DOE directed the Panel to use the same electricity pricing in its base case as was used in the DOE H2A Case. Thus both use the EIA 2005 AEO High A forecast for electricity prices that use 2005 through 2025 as the analysis period. The 2005 price is $\$ 0.055 / \mathrm{kWh}$. The price drops somewhat and then increases to $\$ 0.056 / \mathrm{kWh}$ by 2025 . The average cost over the entire period is about $\$ 0.053 / \mathrm{kWh}$.

- Production Maintenance Costs: The participating electrolyzer vendors provided a range of production maintenance costs, all of which were significantly less than that used in the DOE H2A Case. A key advantage of electrolyzers is that they have no moving parts except for some in the balance-of-plant equipment. The primary issue with this technology is the lifetime of the cell stacks (discussed below). The vendors had actual data based on their current commercial electrolyzers. The Panel considered $2 \%$ of purchased capital to be a reasonable base-case value.

- Electrolyzer Cell Replacement Cost and Frequency: The electrolyzer vendors provided a fairly narrow range for cell replacement frequency -7 to 10 years. The Panel chose to be conservative and use 7 years, because the technology incorporated in this analysis is new state of the art. Durability of electrolyzers using this technology still must be proven. The 
Panel, using similar reasoning, also was somewhat conservative in its choice of the cost of this replacement as a percentage of the purchased capital.

- Production operating capacity factor and the $\mathrm{C} / \mathrm{S} / \mathrm{D}$ low pressure storage quantity are discussed in Section 4.2.1.

- Working capital is discussed in Section 4.1.5.

- The $\mathrm{C} / \mathrm{S} / \mathrm{D}$ electrical upgrade is discussed in Section 4.2.2.

- Process Water, Cooling Water, and Other Variable Costs: These variable costs have only a minor impact on total hydrogen cost. The range provided to the Panel by vendors for the process water requirement was fairly narrow and the Panel selected the middle of the range. Cooling water requirements can be considerable depending on the cooling approach used (discussed in Section 4.2.3). It is expected that forecourts would use some active cooling approach to minimize water use, but the capital and operating cost for this would be small. Rather than explicitly trying to estimate these costs, the Panel chose simply to include standard cooling water requirements as a surrogate. The DOE H2A Case had included some costs for replacing the alkaline solution for alkaline systems and other miscellaneous variable costs. From discussions both with vendors and internally, the Panel concluded any such costs would be negligible.

\subsubsection{Central Production Base Case}

The Panel believes that, since 2005, technology has advanced significantly in PEM and alkaline electrolysis applicable to central hydrogen production, as represented in the estimated cost reduction and as discussed in Section 4.1.1. The net change in hydrogen cost between the DOE published H2A Case for 2005 technology and the Panel's base case for current (2009) state-ofthe art technology is a reduction of $\$ 1.51$ (see Table 4).

The DOE H2A Current Central Hydrogen Production from Grid Electrolysis version 2.1.1 was the starting point the Panel used for its analysis. All of the input parameters used in this case were reviewed and compared with all the information gathered as well as Panel members' own knowledge and experience. The Panel modified the parameters as appropriate to represent its conclusions for state-of-the-art 2009 electrolysis technology to establish a base case. The changes the Panel made that had the most significant impact on the hydrogen cost were production capital cost, energy usage, and electricity price.

Many of the H2A model input parameters were left unchanged as deemed appropriate. This included all of the standard "H2A Default Values" for financial inputs, fixed costs, and operating costs with the one exception of working capital (as discussed in Section 4.1.5). Also included were other inputs such as parameters concerning construction time and start-up, and some of the other variable costs. The inputs that were changed are shown in Table 4 . This table also shows the range of values for these inputs received from the electrolyzer companies, the values from the DOE H2A Current Central Hydrogen Production from Grid Electrolysis version 2.1.1 (H2A Case) that represents 2005 technology, and the Panel's base-case values. This table shows the stepwise and cumulative change in the hydrogen cost starting with the H2A Case. 
Table 4. Panel Central Production Base Case

\begin{tabular}{|c|c|c|c|c|c|}
\hline Central Production & Vendor Range & Panel Base Case & H2A case & H2 Cost (\$/kg) & Delta \\
\hline \multicolumn{4}{|l|}{ Current (2005) H2A Case } & $\$ 4.50$ & \\
\hline Total Depreciable Capital Cost (M\$̧) & $\$ 17.9$ to $\$ 56.3$ & $\$ 50$ & $\$ 110.4 \mathrm{M}$ & $\$ 3.74$ & $(\$ 0.76)$ \\
\hline Energy use $(\mathrm{kWh} / \mathrm{kg})$ & 48 to 59 & 50 & 53.44 & $\$ 3.55$ & $(\$ 0.19)$ \\
\hline Electricity Price & NA & $0.045 \$ / \mathrm{kWh}$ & $\$ .055 / \mathrm{kWh}$ EIA & $\$ 3.13$ & $(\$ 0.42)$ \\
\hline $\begin{array}{l}\text { Electrolyzer Cells Capital Replacement (M\$) } \\
\text { (\% of Total Depreciable Capital) }\end{array}$ & $\begin{array}{l}\$ 1.2 \text { to } \$ 19.7 \\
6 \% \text { to } 35 \%\end{array}$ & $\begin{array}{c}\$ 12.5 \\
25 \%\end{array}$ & $\begin{array}{c}\$ 28.3 \\
26 \%\end{array}$ & $\$ 3.13$ & $\$ 0.00$ \\
\hline Eletrolyzer Cell Replacement Interval (yrs) & 7 to 10 & 7 & 10 & $\$ 3.17$ & $\$ 0.04$ \\
\hline Working Capital (\% of Change in Operating Costs) & NA & $5 \%$ & $15 \%$ & $\$ 3.12$ & $(\$ 0.05)$ \\
\hline FTE's & 5 to 10 & 10 & 3 & $\$ 3.18$ & $\$ 0.06$ \\
\hline Production Maintenance (\% of Total Depr. Capital) & $1 \%$ to $3 \%$ & $2 \%$ & $2.6 \%$ & $\$ 3.16$ & $(\$ 0.02)$ \\
\hline Process Water (gal/kg-H2) & 2.6 to 2.9 & 2.5 & 2.9 & $\$ 3.16$ & $\$ 0.00$ \\
\hline Cooling Water (gal/kg-H2) & 0.1 to 290 & 290 & 294 & $\$ 3.16$ & $\$ 0.00$ \\
\hline All other Variable Costs (k\$/yr) & NG & $\$ 0$ & $\$ 433$ & $\$ 3.13$ & $(\$ 0.03)$ \\
\hline Op. Capacity Factor (\%) & $98-99.5$ & $98 \%$ & $97 \%$ & $\$ 3.13$ & $\$ 0.00$ \\
\hline Start-up time (months) & 6 & 6 & 24.00 & $\$ 2.99$ & $(\$ 0.14)$ \\
\hline Land Cost (\$/acre) & NA & $\$ 50,000$ & $\$ 5,000$ & $\$ 3.00$ & $\$ 0.01$ \\
\hline \multicolumn{4}{|l|}{ Total Cumulative Change } & (\$1.51) & \\
\hline
\end{tabular}

As Table 4 shows, and as noted above, the changes the Panel made that had the most significant impact on the hydrogen cost were production capital cost, energy use, and electricity price. These variables dominate the cost of hydrogen production from electrolysis. The rationale for the Panel's choices of parameters for its base case is discussed below.

- The Panel's basis for the total depreciable capital and total energy use is discussed at length in Section 4.1.2 and Section 4.1.4, respectively.

- Electricity Price: The DOE charter to the Panel was to estimate the current state-of-the art cost of hydrogen from a central electrolysis facility that had access to renewable electricity at all times. The DOE provided a cost of electricity of $\$ 0.045 / \mathrm{kWh}$ held constant over the analysis period to represent this scenario. This value was based on the following.

- The DOE estimate for the gate cost of electricity from a wind farm is $\$ 0.0405 / \mathrm{kWh}$.

- The EIA AEO 2009 projection for the cost of electricity transmission is $\$ 0.007$ to $\$ 0.009 / \mathrm{kWh}$ for 2006-2009. Other projections range from $\$ 0.006 / \mathrm{kWh}$ to $\$ 0.009 / \mathrm{kWh}$. DOE chose to use a value of $\$ 0.007 / \mathrm{kWh}$.

- It is assumed that the electrolysis plant is located at a wind farm. The wind farm has an operating capacity of $40 \%$ and supplies $\$ 0.0405 / \mathrm{kWh}$ electricity to the electrolysis plant when operating. The electrolysis plant receives the remainder of its electricity $(60 \%)$ from other wind plants at a price of $\$ 0.0475$.

- Electrolyzer Cell Replacement Cost and Frequency: The electrolyzer vendors provided a fairly narrow range for cell replacement frequency -7 to 10 years. The Panel chose to be conservative and use 7 years because the technology being incorporated in this analysis is new state of the art. Durability of electrolyzers using this technology still must be proven. Using similar reasoning, the Panel also was somewhat conservative in its choice of the cost of this replacement as a percentage of the purchased capital versus the range provided by the vendors. The actual percentage used is less than that used in the forecourt 
case because the forecourt case is based on purchased capital and the central case is based on total depreciable capital of the entire central plant.

- Working capital is discussed in Section 4.1.5.

- Labor: Full-time equivalents (FTEs) is the number of people needed to operate the full plant. A facility operating 24 hours per day, 7 days a week requires five full shifts of staffing. Thus 10 FTEs only represents 2 people at the plant at all times. The Panel thinks this is the appropriate staffing level. This category does have a measurable impact on hydrogen costs.

- Production Maintenance Costs: The electrolyzer vendors provided a narrow range for production maintenance costs. A key advantage of electrolyzers is that they have no moving parts except in the balance-of-plant equipment. The primary issue with this technology is the lifetime of the cell stacks (discussed above). The vendors had actual data based on their current commercial electrolyzers. The Panel determined that $2 \%$ of total depreciable capital was a reasonable base-case value.

- Process Water, Cooling Water, and Other Variable Costs: These costs were found to have only a minor impact on costs. The range vendors provided to the Panel for the process water requirement was fairly narrow, and the Panel selected the middle of the range. Cooling water needs can be considerable depending on the cooling approach taken (discussed in Section 4.3.5). Central plants are expected to use evaporative cooling water towers. Rather than explicitly try to estimate these costs, the Panel simply chose to include once-through cooling water requirements as a surrogate. The DOE H2A Case had included some costs for replacing the alkaline solution for alkaline systems and other miscellaneous variable costs. From discussions both with vendors and internally, the Panel concluded any such costs would be negligible.

- Operating capacity is discussed in Section 4.3.1.

- Start-up time for an electrolyzer facility is considered by the vendors to be straightforward and the Panel agrees. This is another advantage of this technology for hydrogen production. The reduction from 24 months for the DOE H2A Case to 6 months reduces the hydrogen cost by a significant amount $(\$ 0.14 / \mathrm{kg})$.

- Land costs are discussed in Section 4.3.2.

\subsection{Sensitivity Analysis}

\subsubsection{Distributed Forecourt Production Sensitivity Analysis}

Table 5 shows what the Panel has chosen as its best estimate for the tenth-percentile and ninetieth-percentile likely values $(10 \% / 90 \%$ values $)$ for the parameters of importance discussed above in the forecourt production base case (Section 5.3.1). The 10\% level is an estimate of the value of a parameter such that there only is a $10 \%$ chance that the value is less. Similarly, the $90 \%$ level is the value of a parameter such that there only is a $10 \%$ chance the value is greater. These are useful and statistically meaningful points to use in a sensitivity analysis. Table 5 also shows the $\mathrm{H} 2 \mathrm{~A}$ model results for the cost of hydrogen at these $10 \%$ / $90 \%$ parameter levels for the current (2009) state-of-the-art forecourt production unit, C/S/D, and for the total forecourt station. These results represent changing only the one parameter in that table row from the Panel base case (i.e., one variable at a time). Figure 6 plots these values as a tornado chart. 
Table 5. Forecourt Electrolysis Panel Base Case Sensitivity Analysis

\begin{tabular}{|c|c|c|c|c|c|}
\hline Forecourt & Panel $10 \%$ & Panel 90\% & $\begin{array}{l}\text { Panel Result Range } \\
\text { Production }(\$ / \mathrm{kg})\end{array}$ & $\begin{array}{c}\text { Panel Result Range } \\
\mathrm{C} / \mathrm{s} / \mathrm{D}(\mathbf{S} / \mathrm{kg})\end{array}$ & \begin{tabular}{|l} 
Panel Result Range \\
Total (\$//g)
\end{tabular} \\
\hline Production Purchased Capital Cost (M\$) & $\$ 0.55$ & $\$ 1.80$ & $\$ 3.05$ to $\$ 3.58$ & $\$ 1.87$ & $\$ 4.92$ to $\$ 5.45$ \\
\hline Total Energy (kWh/kg) & 47.5 & 60 & $\$ 3.19$ to $\$ 3.85$ & $\$ 1.87$ & $\$ 5.06$ to $\$ 5.72$ \\
\hline Electricity Price (\$/kWh) & $\$ 0.03$ & $\$ 0.08$ & $\$ 2.20$ to $\$ 4.70$ & $\$ 1.87$ & $\$ 4.07$ to $\$ 6.57$ \\
\hline Production Maintenance (\% of Purchased Capital) & $1 \%$ & $3 \%$ & $\$ 3.30$ to $\$ 3.35$ & $\$ 1.87$ & $\$ 5.17$ to $\$ 5.22$ \\
\hline $\begin{array}{l}\text { Electrolyzer Cells Capital Replacement } \\
\text { (\% of Total Production Purchased Capital) }\end{array}$ & $10 \%$ & $50 \%$ & $\$ 3.25$ to $\$ 3.36$ & $\$ 1.87$ & $\$ 5.12$ to $\$ 5.23$ \\
\hline Eletrolyzer Cell Replacement Interval (yr) & 5 & 10 & $\$ 3.37$ to $\$ 3.27$ & $\$ 1.87$ & $\$ 5.24$ to $\$ 5.14$ \\
\hline Working Capital (\% of Change in Operating Costs) & $0.50 \%$ & $10 \%$ & $\$ 3.31$ to $\$ 3.36$ & $\$ 1.87$ & $\$ 5.18$ to $\$ 5.23$ \\
\hline Process Water (gal/kg-H2) & 2.4 & 3 & $\$ 3.32$ to $\$ 3.32$ & $\$ 1.87$ & $\$ 5.19$ \\
\hline Cooling Water (gal/kg-H2) & 150 & 330 & $\$ 3.30$ to $\$ 3.32$ & $\$ 1.87$ & $\$ 5.17$ to $\$ 5.19$ \\
\hline
\end{tabular}

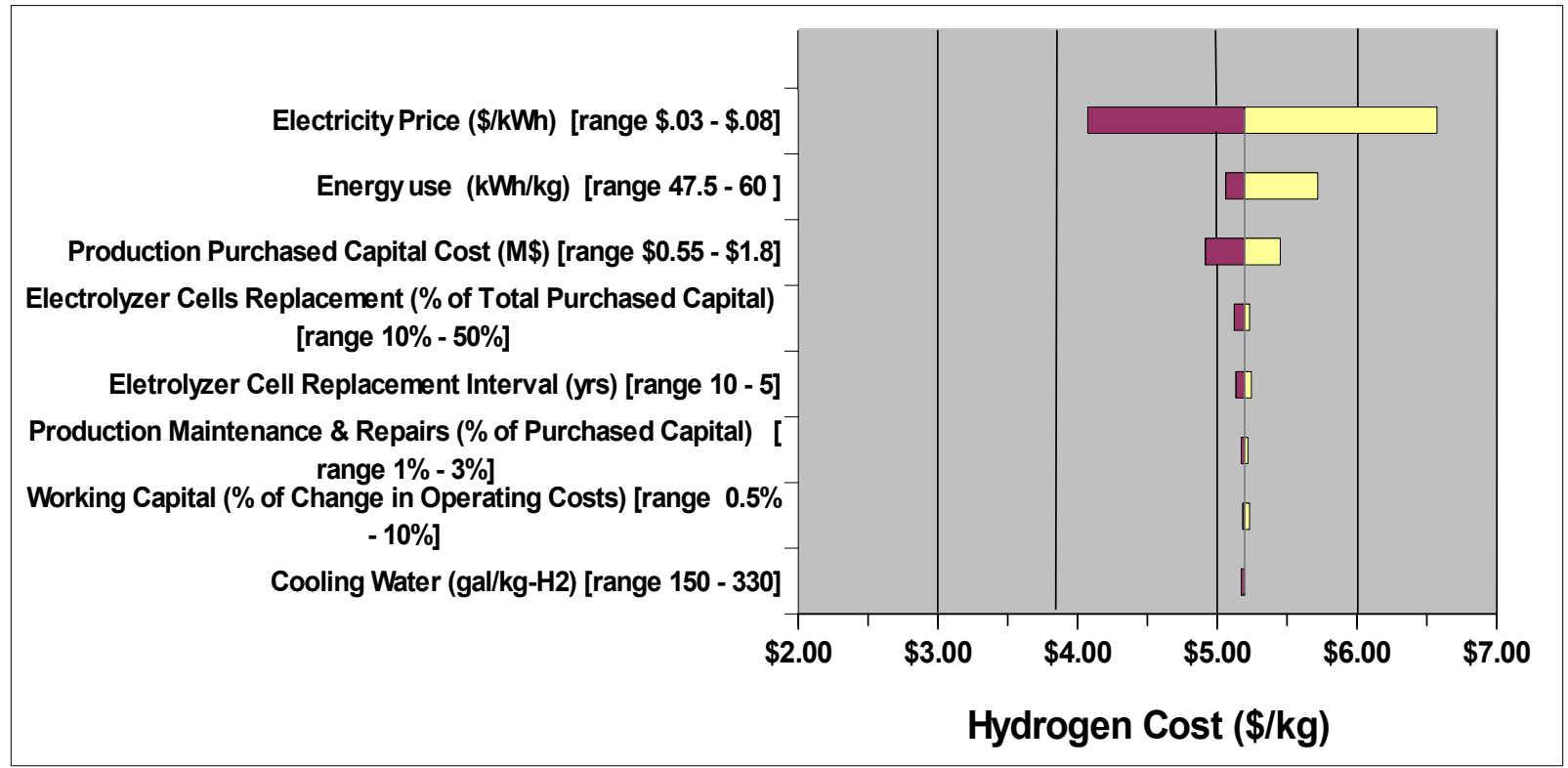

Figure 6. Forecourt electrolysis Panel base case sensitivity analysis tornado chart

Table 5 and Figure 6 use 10\% / 90\% values for all the variables, therefore the length of the bars in the tornado chart represent the relative sensitivity of the hydrogen cost to that variable. Figure 6 clearly shows that electricity price is the most important variable, followed by electricity use, and then by production purchased capital cost. The other variables only make a minor change to the hydrogen cost even at these 10\% / 90\% limits. This can be seen another way by examining Figure 7. This pie chart shows the breakdown of the costs of the production portion of the forecourt ( $\$ 3.32 / \mathrm{kg}$ of hydrogen). This shows that $79 \%$ of the cost is from the cost of the electricity needed, $17 \%$ is from the capital cost, and all the other costs together account for only $4 \%$ of the hydrogen production cost. A reasonable summary of this sensitivity analysis is that, excluding electricity price variations, a reasonable range for the delivered cost of hydrogen from forecourt electrolysis is between $\$ 4.90$ and $\$ 5.70$. 


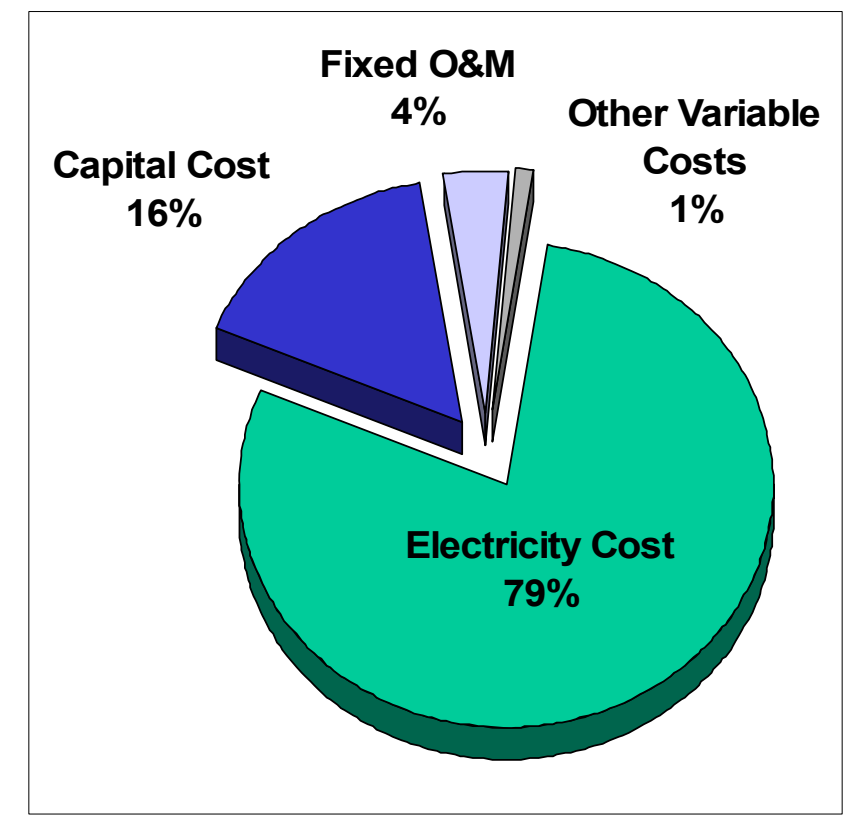

Figure 7. Forecourt production (excluding forecourt $C / S / D$ )—hydrogen cost breakdown

\subsubsection{Central Production Sensitivity Analysis}

Table 6 shows what the Panel has chosen as its best estimate of the 10\% / 90\% values for the parameters of importance discussed above in the central production base case (Section 5.3.2).

Table 6 also shows the H2A model results for the cost of hydrogen at these $10 \% / 90 \%$ parameter levels for the current (2009) state-of-the-art central production. These results represent changing only the one parameter in that table row from the Panel base case. Figure 8 plots these values as tornado chart.

Table 6. Central Electrolysis Panel Base Case Sensitivity Analysis

\begin{tabular}{|l|c|c|c|}
\hline \multicolumn{1}{|c|}{ Central Production } & Panel 10\% & Panel 90\% & Result Range \\
\hline Total Depreciable Capital Cost (M\$) & $\$ 23$ & $\$ 74$ & $\$ 2.72$ to $\$ 3.24$ \\
\hline Energy use (kWh/kg) & 47.5 & 60 & $\$ 2.88$ to $\$ 3.46$ \\
\hline Electricity Price (\$/kWh) & $\$ 0.03$ & $\$ 0.08$ & $\$ 2.23$ to $\$ 4.78$ \\
\hline Electrolyzer Cells Capital Replacement & $10 \%$ & $50 \%$ & $\$ 2.94$ to $\$ 3.09$ \\
\hline Eletrolyzer Cell Replacement Interval (yrs) & 5 & 10 & $\$ 3.05$ to $\$ 2.96$ \\
\hline Working Capital (\% of Change in Operating Costs) & $3 \%$ & $12 \%$ & $\$ 3.00$ to $\$ 3.03$ \\
\hline FTE's & 10 & 25 & $\$ 3.00$ to $\$ 3.10$ \\
\hline Production Maintenance (\% of Total Depr. Capital) & $1 \%$ & $5 \%$ & $\$ 2.97$ to $\$ 3.08$ \\
\hline Process Water (gal/kg-H2) & 2.4 & 3 & $\$ 3.00$ to $\$ 3.00$ \\
\hline Cooling Water (gal/kg-H2) & 150 & 330 & $\$ 3.00$ to $\$ 3.00$ \\
\hline Op. Capacity Factor (\%) & $96 \%$ & $99.50 \%$ & $\$ 3.01$ to $\$ 2.99$ \\
\hline Start-up time (months) & 4 & 12 & $\$ 2.98$ to $\$ 3.04$ \\
\hline Land Cost (\$)/acre) & $\$ 5,000$ & $\$ 200,000$ & $\$ 3.00$ to $\$ 3.00$ \\
\hline
\end{tabular}




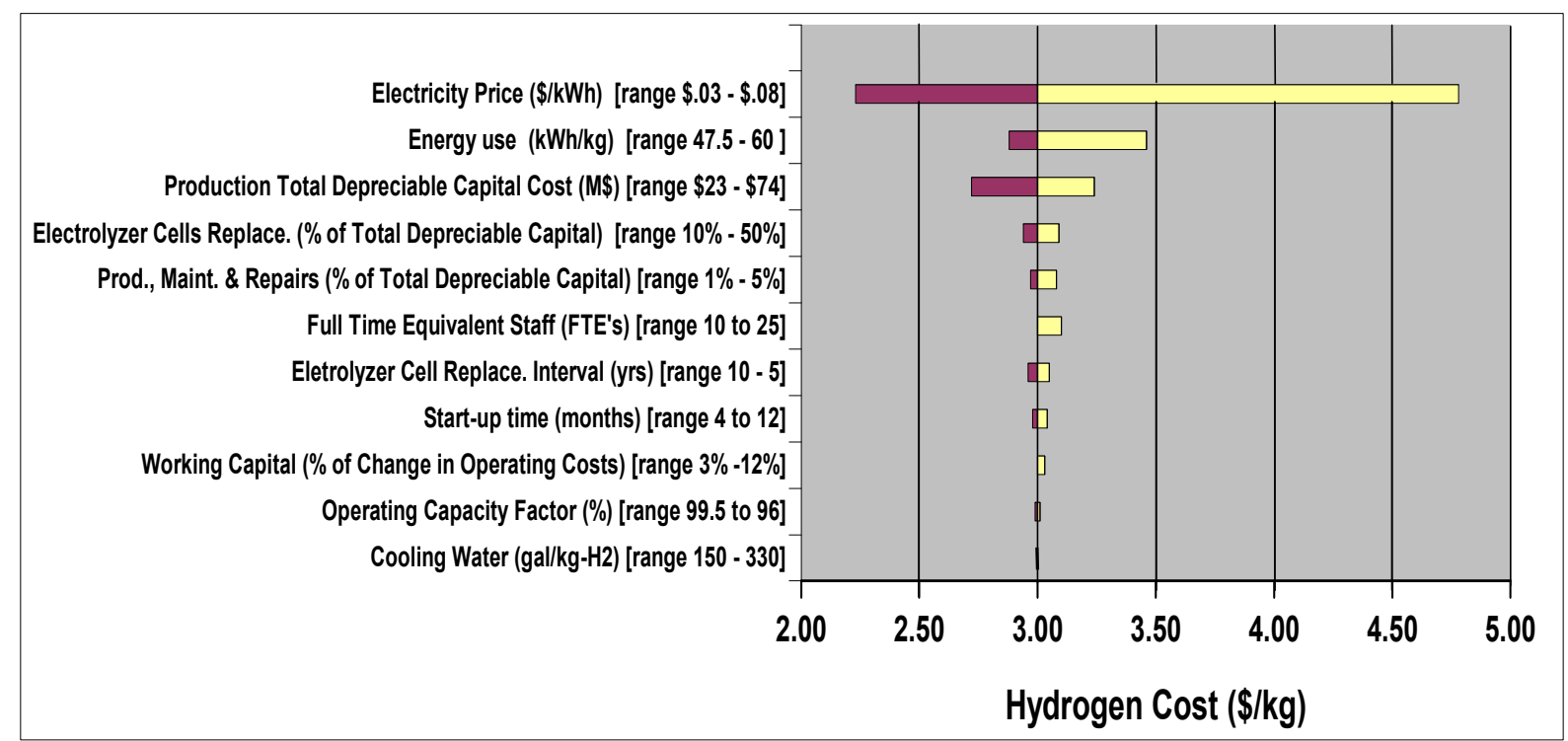

Figure 8. Central electrolysis Panel base case sensitivity analysis tornado chart

As seen for the forecourt case, Figure 8 clearly shows that electricity price is the most important variable, followed by electricity use and then production purchased capital cost for central electrolysis. For the central case, electrolyzer cell replacement costs and intervals and plant staffing also can have a measurable impact on the hydrogen cost. The other variables make only a very minor change to the hydrogen cost, even at the $10 \% / 90 \%$ limits. This can be seen another way in Figure 9. This pie chart shows the breakdown of the costs of central electrolysis hydrogen production. This shows that $79 \%$ of the cost is from the cost of the electricity needed, $16 \%$ is from the capital cost, $5 \%$ is from fixed O\&M costs including staffing, and all the other costs together account for only $1 \%$ of the hydrogen production cost. A reasonable summary of this sensitivity analysis is that - excluding electricity price variations - a reasonable range for the plant gate cost of hydrogen from central electrolysis is between $\$ 2.70$ and $\$ 3.50$.

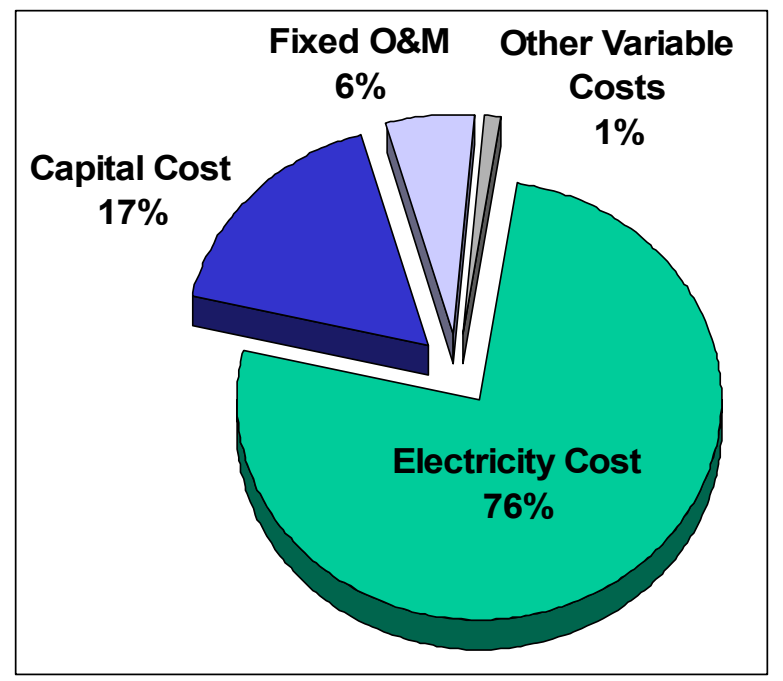

Figure 9. Central production hydrogen cost breakdown 


\section{Results and the Impact of Electricity Prices}

The Panel's base-case cost for hydrogen from forecourt distributed electrolysis at an electricity price of $\$ 0.053 / \mathrm{kWh}$ is $\$ 5.19$ per kilogram of hydrogen. This compares with the DOE published $\mathrm{H} 2 \mathrm{~A}$ Case of this scenario representing 2005 technology of $\$ 6.05 / \mathrm{kg}$ at the same electricity price. This represents significant progress occurring in electrolysis technology since 2005, as discussed in Section 4.1.1. The greatest cost reduction has come from lower capital cost, followed by improved energy efficiency (see Table 3); taken together these account for $93 \%$ of the cost reduction. Remarkable progress has been made in hydrogen electrolysis production.

As discussed in Section 1, these numbers cannot be compared directly with the overall DOE Hydrogen Program forecourt electrolysis delivered hydrogen cost targets because these targets were derived with an older H2A model. The DOE Hydrogen Program, however, does have specific 2014 targets for distributed production capital costs and efficiency. The Panel's results equate to a production capital cost of $\$ 380 / \mathrm{kW}$, which is slightly less than the DOE 2014 target of $\$ 400 / \mathrm{kW}$ for distributed production. The Panel's production efficiency (LHV) of $67 \%$ is only slightly less than the DOE 2014 target of 69\%. The DOE's 2006 status for distributed production is $\$ 665 / \mathrm{kW}$ for capital and $62 \%$ efficiency.

The Panel's base-case cost for hydrogen from central electrolysis at an electricity price of $\$ 0.045 / \mathrm{kWh}$ is $\$ 3.00 / \mathrm{kg}$ of hydrogen. This compares with the DOE published H2A Case of this scenario representing 2005 technology of $\$ 4.50 / \mathrm{kg}$ at an average electricity price of $\$ 0.053 / \mathrm{kWh}$. The difference in electricity price accounts for $\$ 0.42 / \mathrm{kg}$ of the cost reduction. Of the remainder, capital cost reduction contributes the largest portion, followed by energy efficiency and reduced start-up time (see Table 4).

As discussed in Section 1, these numbers cannot be compared directly with the overall DOE Hydrogen Program central electrolysis hydrogen cost targets because these targets were based on a dedicated wind plant electrolysis scenario. The DOE Hydrogen Program, however, does have specific 2014 targets for central production capital costs and efficiency. The Panel's results equate to a production capital cost of $\$ 460 / \mathrm{kW}$ compared to the DOE 2014 target for central production of $\$ 350 / \mathrm{kW}$. The Panel's production efficiency (LHV) of $67 \%$ is only slightly less than the DOE 2014 target of 69\%. The DOE's 2006 status for central production is $\$ 665 / \mathrm{kW}$ for capital and $62 \%$ efficiency.

These conclusions represent remarkable progress made in hydrogen electrolysis production since 2005. They are supported by the technology improvements discussed in Section 4.1.1. Clearly, there is uncertainty in the base-case values, and the technology evaluated has not been proven commercially. In some cases the data is only at the lab scale. In most cases, the full integration of all aspects of the newest technology has not occurred even at the lab scale. The Panel tried to be conservative in its base cases for all of these reasons. The difficulty in projecting from available capital cost information to high-volume manufacturing in a mature market also is discussed in Section 4.1.2. The Panel's selection of $10 \% / 90 \%$ levels for all the key parameters is a way to try to quantify the level of uncertainty in the base-case values as shown in the tornado charts in Figure 7 and Figure 8. 
By far, the uncertainty that has the greatest impact is electricity price. Electricity prices can - and will - be affected by many variables including regional resources; supply and demand, especially at peak times; and the potential impact of carbon policy. Figure 10 shows the Panel's base cases as a function of electricity price. This clearly shows the impact of electricity price on the cost of hydrogen from electrolysis. Production capital cost and energy efficiency also can have a significant uncertainty impact. Electrolysis technology tends to trade off these factors. More capital can be spent to improve efficiency and, conversely, capital cost can be reduced at the expense of some efficiency.

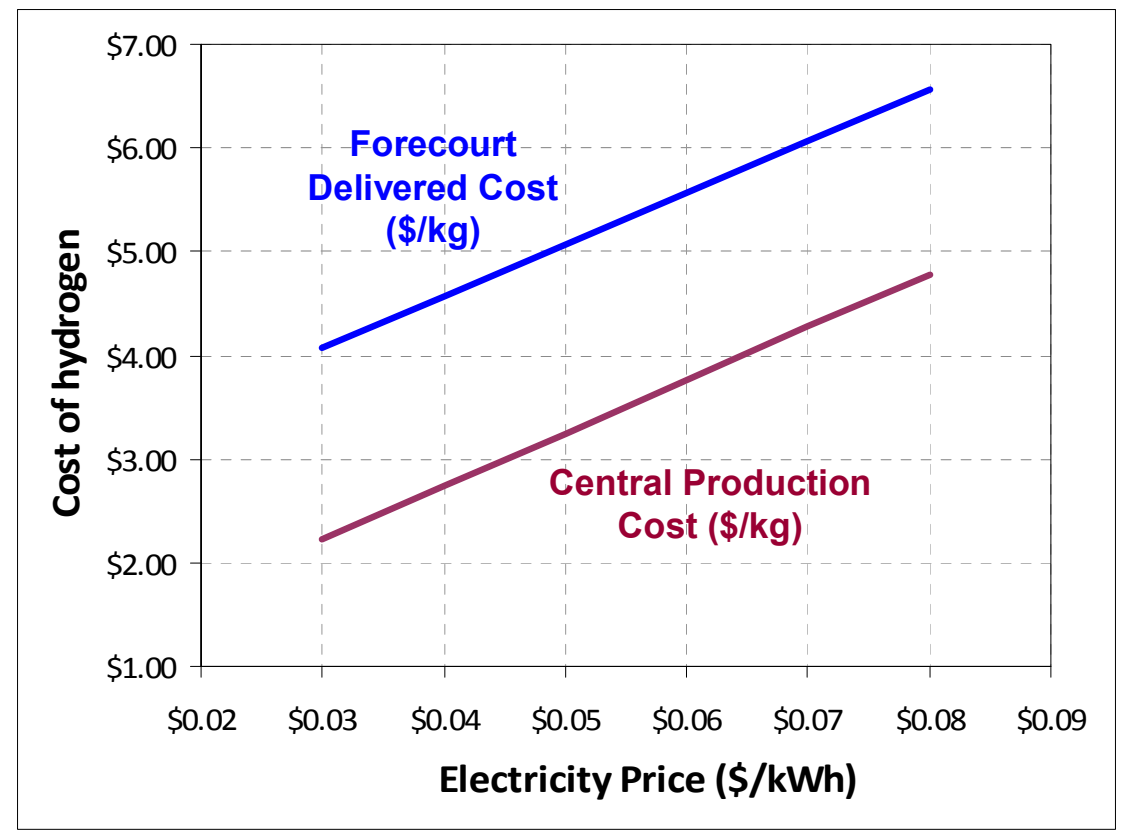

Figure 10. Base cases as a function of electricity price

There is some uncertainty about other parameters for both forecourt and central electrolysis production, but they have less impact. The Panel has made no distinction between PEM and alkaline electrolysis technologies. Although the two technologies are inherently different, the values observed for capital costs and efficiencies overlap.

\section{Opportunities for Future Cost Reductions}

As discussed above, things are well underway toward meeting DOE targets, provided that the technologies currently under development are commercialized successfully. To ensure that this happens, the Panel suggests the following as focal points for development efforts.

- Emphasize full-scale demonstration of new technologies currently being developed.

- Reduce the cost of balance-of-plant items, particularly for power electronics (rectifiers, transformers).

- Develop mass manufacturing methods, including new methods and materials. Evaluate methods used by the fuel cell industry and in other high-volume manufacturing operations. 
- Analyze possible limiting input factors (e.g., certain catalyst components) in the case of large-scale application of technology.

- Design units that have greater capacities, particularly the cell stack. Use the experience in other electrolysis technologies to optimize designs for large capacities (e.g., PEM units based on chlor-alkali design concepts).

- Develop engineering design of large-scale central hydrogen production, including a verified cost estimate of a complete plant.

- Decrease the cost of renewable power. Study the integration of electrolyzers in the development of new renewables and electricity grid plans. As discussed, $80 \%$ of the cost of hydrogen is from the cost of electricity. For hydrogen using electrolysis to be both sustainable and cost effective, the development of renewable power and hydrogen should be seen in context.

- Evaluate DC (direct current) and control integration of renewable power plants (e.g., wind, electrolyzers) to reduce conversion costs. 


\title{
Appendix A. Vendor Questionnaire and Fact Sheet
}

\begin{abstract}
Introduction
We are doing an independent assessment for the Department of Energy (DOE) Hydrogen Program on the current state of the art hydrogen production through electrolysis of water. We are interested in two scales of production; $1,500 \mathrm{~kg} /$ day $(62.5 \mathrm{~kg} / \mathrm{hr})$ design capacity for refueling stations and $50,000 \mathrm{~kg} / \mathrm{day}$ $(2,083 \mathrm{~kg} / \mathrm{hr})$ design capacity for central production. We are interested in both PEM and alkaline electrolysis technology, and recognize that several electrolyzer units may be needed to give the required capacities.

By "state of the art current technology" we mean your best technology that you have demonstrated at least in the laboratory and that you believe you could scale up to commercial electrolysis unit that would have a practical commercial lifetime. Please notice that cost estimates should be provided assuming a mature market (i.e. a demand for 500 stations per year for the forecourt case, for central production a situation where several such plants have been built and this is the $\mathrm{n}^{\text {th }}$ plant).

We would greatly appreciate if you could answer the questions on the following Water Electrolysis Fact Sheet. The attached Guidelines provide information to help you. All information provided will be used by the independent assessment team only, e.g. to provide input into the "H2A" model developed by DOE (see http://www.hydrogen.energy.gov/h2a analysis.html ). Our report will not associate any specific information with any particular company. If you have any questions, please contact us. If you cannot provide helpful information due to its proprietary nature, we are willing to try to work out a nondisclosure agreement with you.
\end{abstract}




\title{
Water Electrolysis Fact Sheet
}

\author{
Manufacturer: \\ Case no.: \\ Type of installation (check one): $\quad$ Forecourt (1,500 kg/day) $\square \quad$ Central (50,000 kg/day) \\ Technology (check one): \\ PEM \\ Alkaline \\ Please attach a concise description of the key features of your technology, including what makes it \\ different/more advanced than other electrolysis technologies. \\ Briefly describe the relative maturity of this technology; at what scale have you successfully \\ demonstrated the key features of your advanced technology (lab, pilot, and electrolyzer cell size $\left[\mathrm{cm}^{2}\right]$ \\ electrolyzer size $[k W])$ etc.:
}

Expected life time of cell stack:

Expected life time of Balance-of-Plant (BOP):

Configuration (for either Forecourt 1,500 kg/day or Central 50,000 kg/day):

Capacity of each electrolyzer ( $\mathrm{kg} \mathrm{H}_{2} /$ day and $\left.\mathrm{kW}\right)$ :

Number of cell stacks per electrolyzer:

Cell size $\left(\mathrm{cm}^{2}\right)$ :

Number of electrolyzers in total installation:

Electrolyzer operating pressure (psi): Hydrogen: Oxygen:

Electrolyzer operating temperature $\left({ }^{0} \mathrm{C}\right)$ :

Current density $\left(\mathrm{mA} / \mathrm{cm}^{2}\right)$ :

Footprint of total installation, including BOP $(\mathrm{ft})$ :

\section{Capital Costs (at developed market)}

Read guidelines regarding market size, definitions, scope, etc.

All costs in current (2009) USD

Electrolyzer units (cell stacks) USD

Compression to 300 psi (where applicable) USD

Balance of Plant (preferably itemized in attachment) USD

Total capital cost: $\quad$ USD

Briefly describe the approach you took to projecting costs to the scale of hydrogen production requested and to high volume manufacture. 
Power consumption

Energy consumption, cell stack

$\mathrm{kWh} / \mathrm{kg} \mathrm{H} 2$ out

Energy consumption, entire plant (including BOP)

$\mathrm{kWh} / \mathrm{kg} \mathrm{H} 2$ out

Please comment on any expected increase of energy consumption over the expected life time due to cell stack degradation:

\section{Operation and maintenance}

Estimated annual maintenance cost

USD/yr or $\quad \%$ of initial capital/yr

Estimated cost of cell stack reactivation/replacement

USD or $\quad \%$ of initial capital replacement interval once every year

\section{Other Costs}

Process Water (gal/ $/ \mathrm{kg} \mathrm{H}_{2}$ out):

Cooling Water (gal/kg $\mathrm{H}_{2}$ out):

Compressed Inert Gas $\left(\mathrm{Nm}^{3} / \mathrm{kg} \mathrm{H}_{2}\right.$ out):

Electrolyte Solution (USD/yr or USD/kg H $\mathrm{H}_{2}$ out) [alkaline case]

Other significant consumables (USD/yr):

For Central Production Case Only

Construction Time (yrs):

Start-up Time (months):

Estimated number full-time O\&M staff needed:

Estimated max. operating capacity/"up-time" (\%)

\section{Current Commercial Product}

What is the largest electrolyzer of similar but less advanced technology than the state of the art technology described in this case that you currently have available for sale ( $\mathrm{kW}$ and $\mathrm{kg}$ of hydrogen/hr):

For current commercial product:

What is the cost of the full unit including the BOP:

USD

$\mathrm{USD} / \mathrm{kW}$

What is the cost of the cell stack alone:

USD/kW

Energy consumption, cell stack:

$\mathrm{kWh} / \mathrm{kg} \mathrm{H} 2$ out

Energy consumption, entire plant (including BOP):

$\mathrm{kWh} / \mathrm{kg} \mathrm{H} 2$ out 


\section{Guidelines to Electrolysis Fact Sheet}

Please express your answers in 2009 USD.

Case no.: Identifier for each of your provided cases, using e.g. your product model or any other designation as a basis. We would like at least two cases submitted (one forecourt case and one for centralized production, see below).

Type: We are interested in two scales of hydrogen production, as specified by DOE: $1500 \mathrm{~kg} / \mathrm{day}$ ( 62.5 $\mathrm{kg} / \mathrm{h})$ design capacity for forecourt refueling stations, and $50,000 \mathrm{~kg} /$ day $(2,083 \mathrm{~kg} / \mathrm{hr})$ design capacity for central hydrogen production. Each needs to include hydrogen compression to at least 300 psi. Cases that provide hydrogen at a pressure $>300 \mathrm{psi}$ up to $1000 \mathrm{psi}$ without post electrolyzer compression will be given credit for the higher outlet pressure. Please complete at least one form for each case, if you consider your technology to be suitable.

Technology: Please check the appropriate box for either PEM or alkaline technology. The attached description of your technology could be common to several or all your cases, please limit your description to one page or less.

Maturity: We are looking at "state of the art current technology", which means the best technology that you have demonstrated at least in the laboratory and that you believe could scale up to a commercial electrolysis unit at the specified capacities. For each case, please provide a description of whether this particular cell size, configuration, current density, etc. has been demonstrated in the lab, in pilot units, or commercial units.

Expected life time: We need an estimate of the time interval between each change of cell stack or other major overhauls or replacements. Please specify which unit(s) is/are considered critical.

Configuration: We expect the indicated capacities may be served by a configuration of several electrolyzer units, each consisting of one or several cell stacks. Please indicate the capacity of each electrolyzer unit, as well as the number of such units, the number of cell stacks in each unit, and the size of the cells.

Operating pressure: Should be given in psi for both the hydrogen and the oxygen side of the electrolysis cell, operating temperature for the cell in ${ }^{0} \mathrm{C}$.. Current density at design capacity should be indicated in $\mathrm{mA} / \mathrm{cm}^{2}$.

Footprint: Should include all auxiliaries, including power electronics, control units, compression to 300 psi, etc.

\section{Capital costs:}

The cost breakdown may be based on your normal procedures, but should as a minimum specify the cost of the core cell stack units and the balance of plant. A more detailed breakdown will be appreciated, please provide extra attachments as needed.

Assume a developed market: For forecourt refueling stations assume a demand for 500 of these stations per year. For central production assume that several such plants have been built and this is the $\mathrm{n}^{\text {th }}$ plant. 
For the Forecourt case, we would like to see the total purchase cost of pre-assembled skids or containers delivered to site. An installation factor of 1.1 will be assumed; please comment if you find this inappropriate for your technology. The forecourt case does not include large storage, compression to pressures needed for refueling vehicles $(6,250 \mathrm{psi})$, and dispensing.

For the Central case, we are looking for the total cost of the project, i.e. for a complete hydrogen plant delivering hydrogen at 300 psi (or higher). Downstream delivery is not included. Please make sure that the cost breakdown gives a clear picture of the way total costs have been estimated, particularly with respect to installation costs, engineering, commissioning, contingencies, etc.

The scope includes:

Electrolyzer units (cell stacks)

Transformer and rectifier, other power electronics

Control system

Water treatment (if needed)

Hydrogen deoxo and drier unit

All interconnecting piping and cabling

Compression to $300 \mathrm{psi}$ (if operating pressure is lower)

Other auxiliaries needed

Buildings/enclosures

\section{but excludes:}

Compression above 300 psi (credit will be given for electrolyzer op. pressure $>300 \mathrm{psi}$ )

Hydrogen storage (except for what may be needed to keep the electrolyzer operation running smoothly)

Dispensers (Forecourt case)

Grid connection for electrical power

Downstream delivery, pipelines etc. (Central case)

Cost of land

Power consumption: Please relate all energy consumption figures to the net amount of hydrogen being produced. Figures for the "entire plant" relate to the same scope as indicated for the capital costs (e.g. without compression above 300 psi unless this higher pressure is inherent to the electrolyzer itself). For some technologies there is a significant shift in power consumption over the life of the cell stack; please give a verbal description of such change.

Operation and maintenance: The estimated annual maintenance cost relates to an average year. Cost of replacement of the cell stacks or cells on a periodic basis is specified on the following lines, including an expected frequency of such changes. Both numbers may be given in USD or as a percentage of the initial capital cost of the entire plant. For the central production plant, we also would like an estimate of the number of full time staff needed for normal operation of the plant.

Operating capacity: Provide an estimate of the availability of hydrogen production, as \% of theoretical capacity, taking into account only the operations of the total electrolyzer plant itself. Variability of the power supply or a variable demand shall not be considered. 


\section{Current commercial product:}

This section should describe your currently available commercial technology. The capacity, cost and energy consumption relate to one complete unit (with one or several cell stacks). If you fill in forms for both the Forecourt and Central case, the data for the current commercial product only needs to be specified once.

General: Any additional information you consider relevant will be appreciated. Examples are technology details, specific advantages of your technology, areas of current development, scale-up challenges, cost uncertainties, potential for future cost savings, manufacturing issues etc. 


\title{
Appendix B. Capacity Factor and Storage
}

\author{
Distributed Hydrogen Production at Refueling Stations: Impact of Supply and \\ Demand Variations on Capacity Factor Calculations and Storage Requirements
}

\section{Amgad Elgowainy and Brian James Argonne National Laboratory}

Distributed hydrogen production is most commonly achieved through natural gas reforming or water electrolysis at the refueling station site. The production unit is capable of producing hydrogen at specific daily rate (capacity). Because hydrogen production units at refueling stations would require maintenance, both scheduled and unscheduled, its capacity would not be fully utilized throughout the year. Furthermore, seasonal variation of the demand of hydrogen vehicles would result in lower utilization of production capacity during low seasonal demand which occurs typically in the winter. This results in an annual capacity factor of less than $100 \%$.

In addition to the seasonal demand variation, hydrogen demand varies from day to day throughout a typical week, and hour by hour throughout a typical day. To eliminate the impact of such short-term demand variations on production capacity utilization and operational efficiency, buffer storage tanks could be employed to absorb excess production output during times of low demand and to supplement the production output during times of peak demand. Such buffer storage could also be sized to hold enough charge to keep the station operational during unscheduled outages if the duration of such outages is expected to be relatively short (e.g., less than 24 hours).

In the rest of this document, a methodology to calculate the annual capacity factor of the production unit and the storage requirement is explained in details. The impact of the parameters that define the supply and demand variations are quantitatively assessed through a set of simple equations and example $\mathrm{H} 2 \mathrm{~A}$ assumptions. The capacity factor (CF) calculation methodology is first introduced, followed by a methodology to calculate the storage capacity at the refueling station.

\section{Capacity Factor Calculation}

Figure 11 depicts the production unit capacity, the satisfied demand (yellow area), and the unutilized capacity (gray area) over an entire year. Hydrogen demand is assumed to be greater in the summer and lower in the winter as compared to the rest of the year (fall and spring). The production unit scheduled maintenance is assumed to occur during the low demand season (winter). An unplanned outage of the production unit is assumed to occur at a typical frequency. Therefore the production unit needs to produce an excess amount of hydrogen and compress it to buffer storage on a daily basis during the operational time between unscheduled outages; then recuperate that amount to satisfy the station demand during the downtime of the production unit. The buffer storage requirement is implied by the gray-colored area that is constrained between the production daily capacity line and the summer daily demand line at the top of Figure 11. 


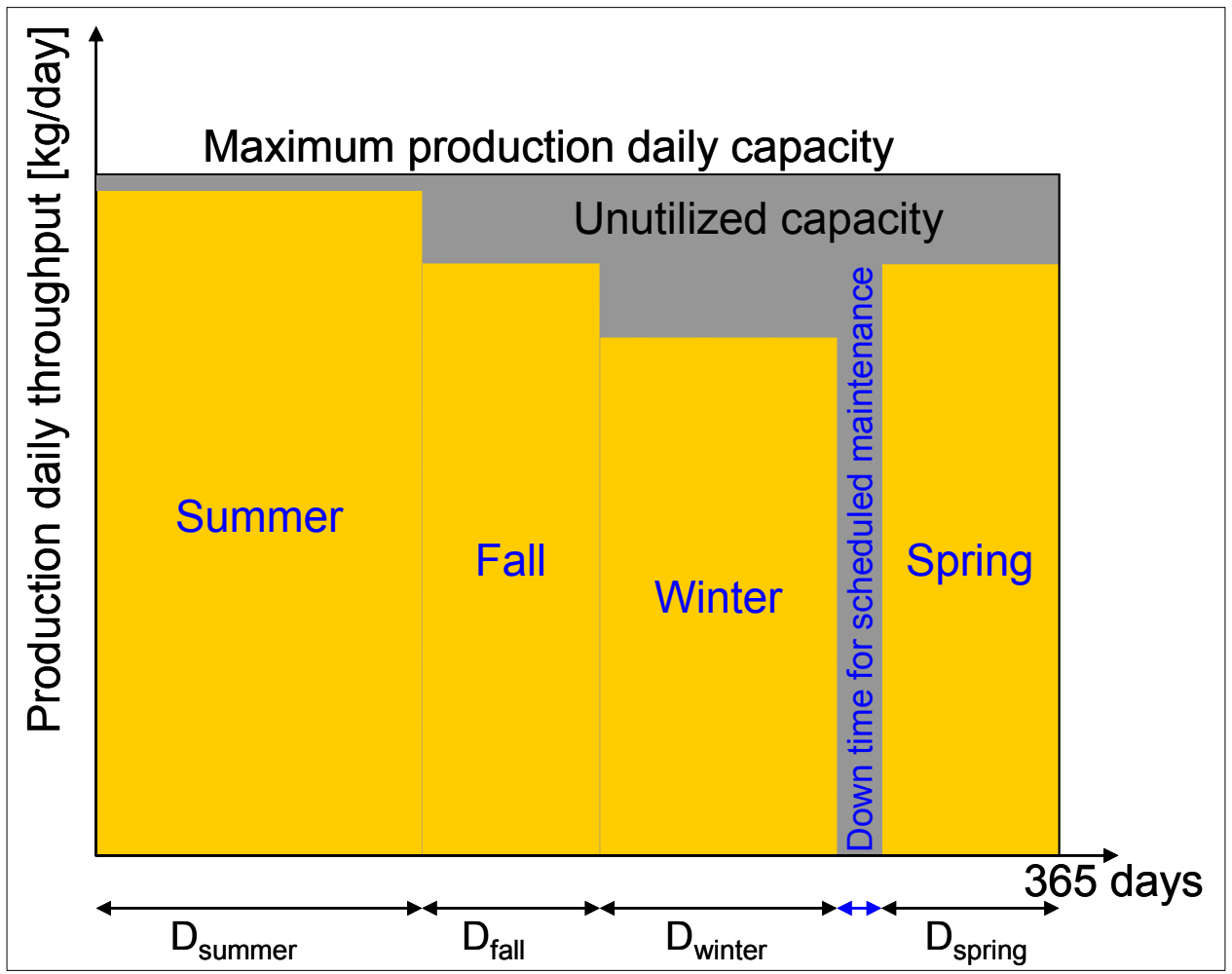

Figure 11. Seasonal demand variation and scheduled outage

The annual capacity factor for the production unit can be simply calculated by dividing the yellow area by the total area of Figure 11 . This can be represented mathematically by the following equation.

$$
\text { Capacity factor }(\mathrm{CF})=\frac{\mathrm{DD}_{\mathrm{FS}}\left[\mathrm{D}_{\text {fall }}+\mathrm{D}_{\text {spring }}+\left(1+P_{\text {summer }}\right) \cdot\left(\mathrm{D}_{\text {summer }}\right)+\left(1-P_{\text {wint } e r}\right) \cdot\left(\mathrm{D}_{\text {winter }}\right)\right]}{\mathrm{DPC} \cdot 365}
$$

Where:

- $\mathrm{DD}_{\mathrm{FS}}$ is the typical (average) daily demand (i.e., in the fall and spring),

- DPC is the daily production capacity,

- $\mathrm{D}_{\text {fall }}$ is the typical number of days for the fall season's demand,

- $\mathrm{D}_{\text {spring }}$ is the typical number of days for the spring season's demand,

- $\mathrm{D}_{\text {summer }}$ is the typical number of days for the summer season's demand,

- $\mathrm{D}_{\text {winter }}$ is the typical number of days for the winter season's demand,

- $\quad P_{\text {summer }}$ is the percentage increase in demand in the summer relative to the average daily demand ( $\left.\mathrm{DD}_{\mathrm{FS}}\right)$, and

- $P_{\text {winter }}$ is the percentage decrease in demand in the winter relative to the average daily demand $\left(\mathrm{DD}_{\mathrm{FS}}\right)$. 
Note that the typical daily demand $\left(\mathrm{DD}_{\mathrm{FS}}\right)$ can be related to the daily production capacity (DPC) by the following formula.

$$
\mathrm{DD}_{\mathrm{FS}}=\frac{\mathrm{DPC}\left[1-\frac{\mathrm{H}_{\text {down }}}{24} \cdot \frac{1}{\mathrm{D}_{\mathrm{op}}}\right]}{\left(1+P_{\text {summer }}\right)}
$$

Where:

- $\mathrm{H}_{\text {down }}$ is the number of hours during unscheduled downtime, and

- $\mathrm{D}_{\mathrm{op}}$ is the minimum number of days between unscheduled plant outages.

Also note that $\mathrm{D}_{\text {fall }}+\mathrm{D}_{\text {spring }}$ can be calculated from the following.

$$
D_{\text {fall }}+D_{\text {spring }}=365-D_{\text {summer }}-D_{\text {winter }}-D_{\text {outage }}
$$

Where $\mathrm{D}_{\text {outage }}$ is the number of days for scheduled production unit maintenance.

The numerator of the $\mathrm{DD}_{\mathrm{FS}}$ formula represents the typical summer daily demand. In particular, the second term in the numerator represents the percentage of DPC that is accumulated daily during the unit's operation between downtimes $\left(\mathrm{D}_{\mathrm{op}}\right)$ to satisfy the station demand during the downtime of the production unit $\left(\mathrm{H}_{\text {down }}\right)$. The above formula only quantifies the lost capacity due to the unplanned outages $\left(\mathrm{H}_{\text {down }}\right.$ each); it does not calculate the storage requirement for each outage (which is the subject of the next section). Thus, the CF equation can be reduced to the following formula.

$$
\begin{aligned}
& \text { Capacity factor }(\mathrm{CF})= \\
& \frac{\left[1-\frac{\mathrm{H}_{\text {down }}}{24} \cdot \frac{1}{D_{o p}}\right] \cdot\left[\left(365-\mathrm{D}_{\text {summer }}-\mathrm{D}_{\text {winter }}-\mathrm{D}_{\text {outage }}\right)+\left(1+P_{\text {summer }}\right) \cdot\left(\mathrm{D}_{\text {summer }}\right)+\left(1-P_{\text {winter }}\right) \cdot\left(\mathrm{D}_{\text {winter }}\right)\right]}{\left(1+P_{\text {summer }}\right) \cdot(365)}
\end{aligned}
$$

It should be noted that the minimum time between unscheduled plant outages $\left(D_{o p}\right)$ significantly impacts the capacity factor of the production unit.

The following default assumptions are made in the H2A model for distributed hydrogen production.

- $\mathrm{D}_{\text {summer }} 120$ days,

- $\quad P_{\text {summer }}=10 \%$,

- $\mathrm{D}_{\text {winter }}=120$ days, and

- $P_{\text {winter }}=10 \%$. 
The following assumptions are recommended for distributed electrolysis hydrogen production by the Electrolysis Hydrogen Production Independent Assessment Panel.

- $\mathrm{H}_{\mathrm{down}}=14 \mathrm{hrs}$,

- $\quad \mathrm{D}_{\mathrm{op}}=30$ days, and

- $\mathrm{D}_{\text {outage }}=5$ days.

Based on the above $\mathrm{CF}$ equation and according to these $\mathrm{H} 2 \mathrm{~A}$ default assumptions, $88 \%$ of the production unit annual capacity could be utilized to satisfy the assumed hydrogen seasonal demand.

\section{Storage Requirement Calculation}

To achieve high utilization (CF) of the production unit, onsite storage is needed to satisfy three main variations in demand and supply: daily variation of demand, hourly variation of demand, and unplanned interruption of supply.

\section{Daily Variation of Demand}

Figure 12 shows the typical daily demand variation over a week as obtained from Chevron. The demand on Thursday and Friday exceeds the average daily demand by $5 \%$ and $8 \%$, respectively. This $13 \%$ of above-average demand corresponds to below-average demand on Monday, Tuesday, and Saturday. Thus, the production amount in excess of Monday, Tuesday, and Saturday demand is compressed into storage and is recovered from storage during above-average demand on Thursday and Friday. To be conservative, the stored amount is calculated to handle $13 \%$ of a "summer" daily demand.

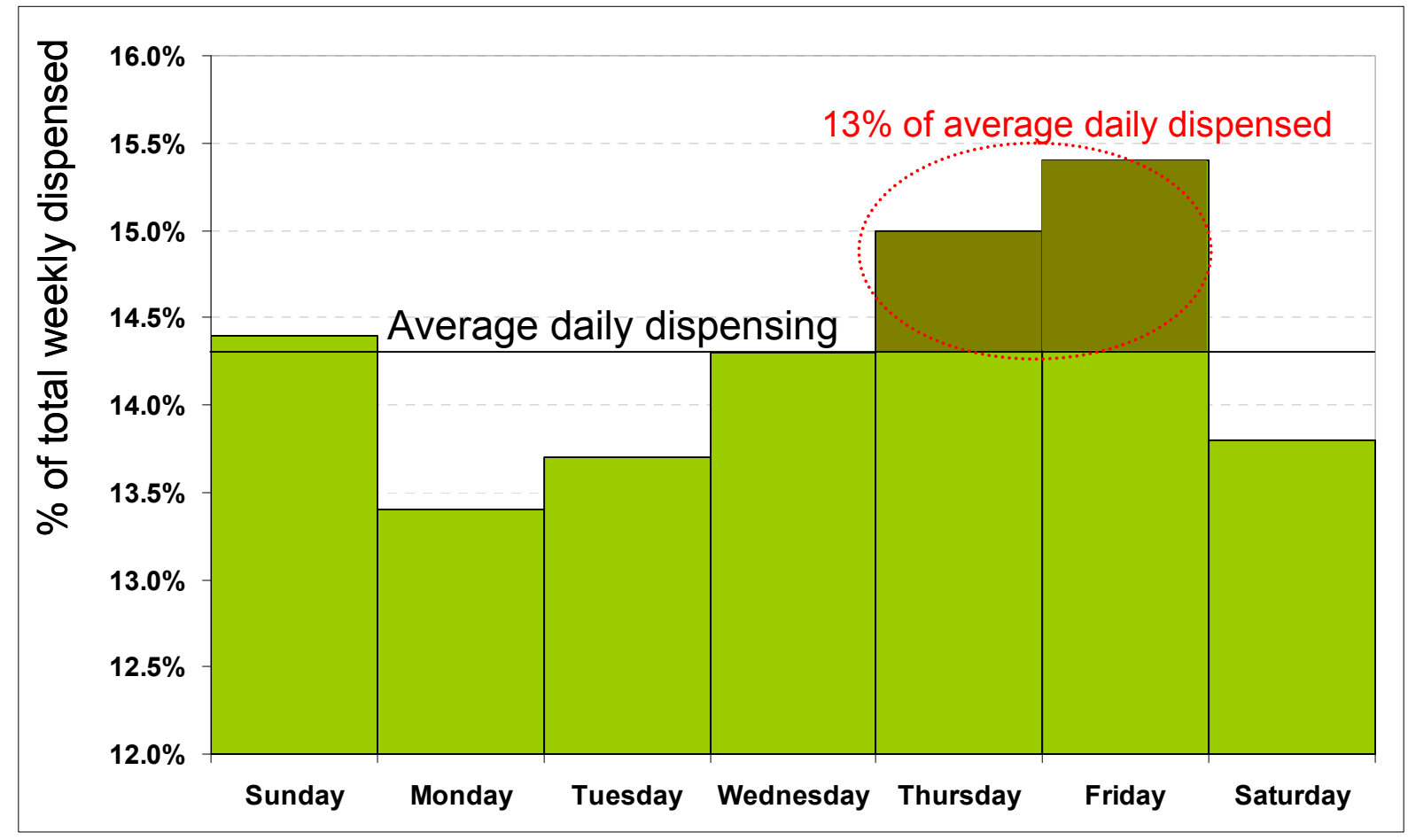

Figure 12. Daily demand variation 


\section{Hourly Variation of Demand}

Figure 13 shows the typical hourly demand variation over a day (e.g., Friday) as provided by Chevron. The average hourly demand over 24 hours is $4.17 \%$ (i.e., $1 / 24$ ) as shown in the figure. However, the actual demand peaks above the average from 8:00 a.m. through 9:00 p.m. The corresponding below-average demand occurs between 9:00 p.m. and 8:00 a.m. Thus, onsite storage is required to store hydrogen from the production unit during off-peak demand hours and to supplement the production unit during peak demand hours. The stored amount can be easily calculated by integrating the area between the demand profile and the average demand line in Figure 13. In general, the storage requirement to handle the increase in hourly demand during peak demand hours of the day can be calculated as follows.

$$
\mathrm{DD}_{\text {peak }}=\sum_{h r=1}^{h r=24} \max \left[\left(\mathrm{DD}_{\mathrm{hr}}-\mathrm{DD}_{\mathrm{hr}, \mathrm{ave}}\right), 0\right]
$$

Where:

- $\mathrm{DD}_{\mathrm{hr}}$ is the hourly demand for each hour of the day, and

- $\mathrm{DD}_{\mathrm{hr} \text {,ave }}$ is the average hourly demand over 24 hours.

It should be noted that actual storage capacity would be greater than the amount calculated by the above formula due to the impact of the heel pressure on the usable capacity of the storage tank. For the demand profile of Figure 13, this area is approximately one-third of the total daily demand. To be conservative, the stored amount is calculated to handle one-third of a "summer" daily demand.

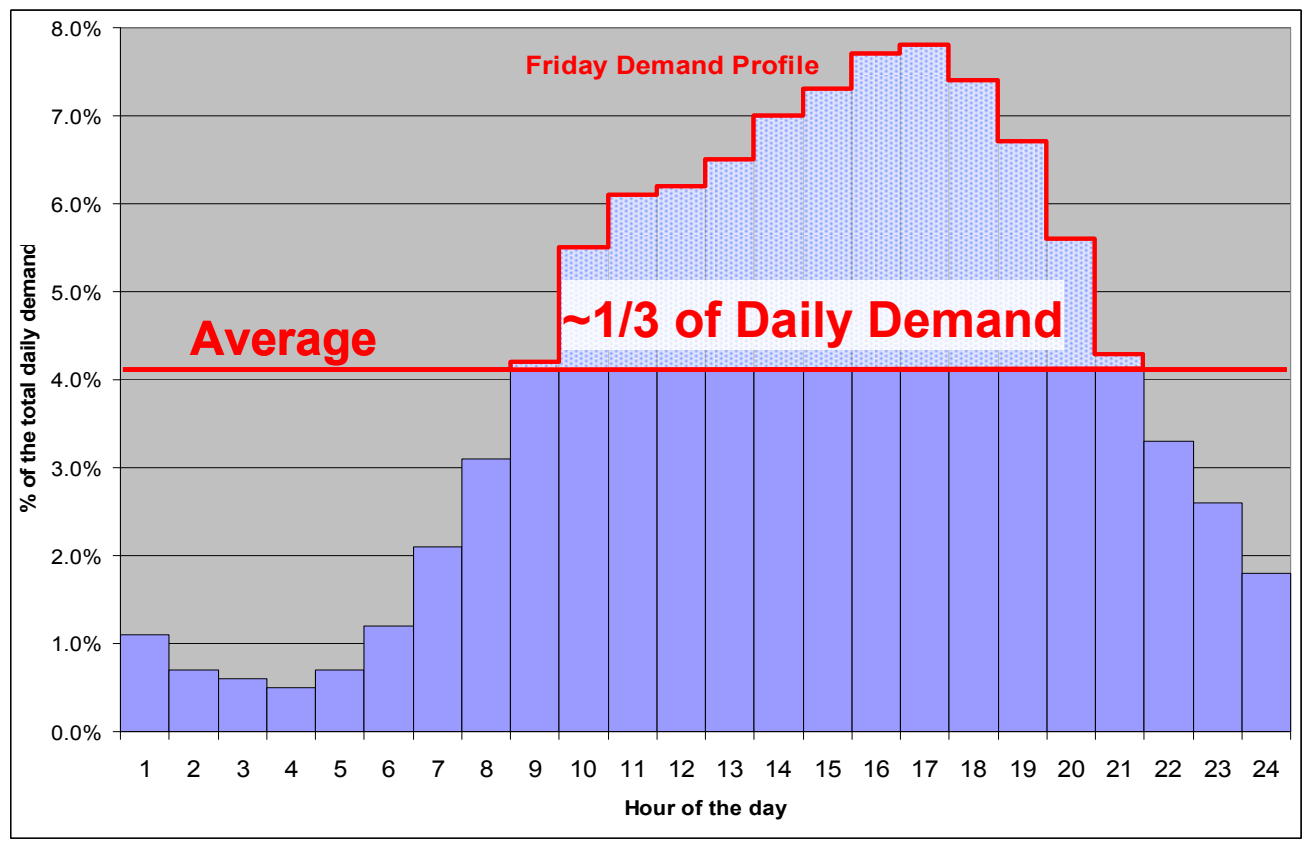

Figure 13. Hourly demand variation 


\section{Unplanned Interruption of Supply (Unscheduled Plant Outages)}

$\mathrm{H} 2 \mathrm{~A}$ assumes unscheduled plant outages of $\mathrm{H}_{\text {down }}$ continuous hours occurring between a minimum duration of $\mathrm{D}_{\mathrm{op}}$. To maintain the refueling operation at the station, enough storage should be available to handle such interruption of supply. When the unscheduled outage occurs, the buffer storage should be able to handle the worst case scenario (i.e., when outage occurs during the peak hours of demand for a summer day). Figure 14, shows an example for the default assumption $\left(\mathrm{H}_{\text {down }}=14 \mathrm{hrs}\right)$ used in the $\mathrm{CF}$ calculation above. The worst case scenario occurs when production is out of operation during the peak 14 hours of demand (8:00 a.m. to 10:00 p.m.). Based on the Chevron demand profile shown in Figure 14, the critical 14 hours of supply interruption requires that the storage provides $6 / 7$ (or $86 \%$ ) of the total daily demand. Figure 12, Figure 13, and Figure 14 provide sufficient information to estimate the required onsite storage. The usable storage can be calculated according to the following formula.

$$
\text { Usable Storage }=\left[P_{\text {week }}+\max \left(P_{\text {day }}, P_{\text {down }}\right)\right]\left(1+P_{\text {summer }}\right) D D_{F S}
$$

Where:

- $\quad P_{\text {week }}$ is the maximum increase in demand above the average daily demand as a percentage of the average daily demand over a one-week period;

- $\quad P_{\text {day }}$ is the maximum increase in demand above the average hourly demand as a percentage of the total daily demand over a 24-hour period; and

- $\quad P_{\text {down }}$ is the maximum deficiency in daily supply as a percentage of the total daily demand due to an unscheduled production outage for a period of $\mathrm{H}_{\text {down }}$ hours.

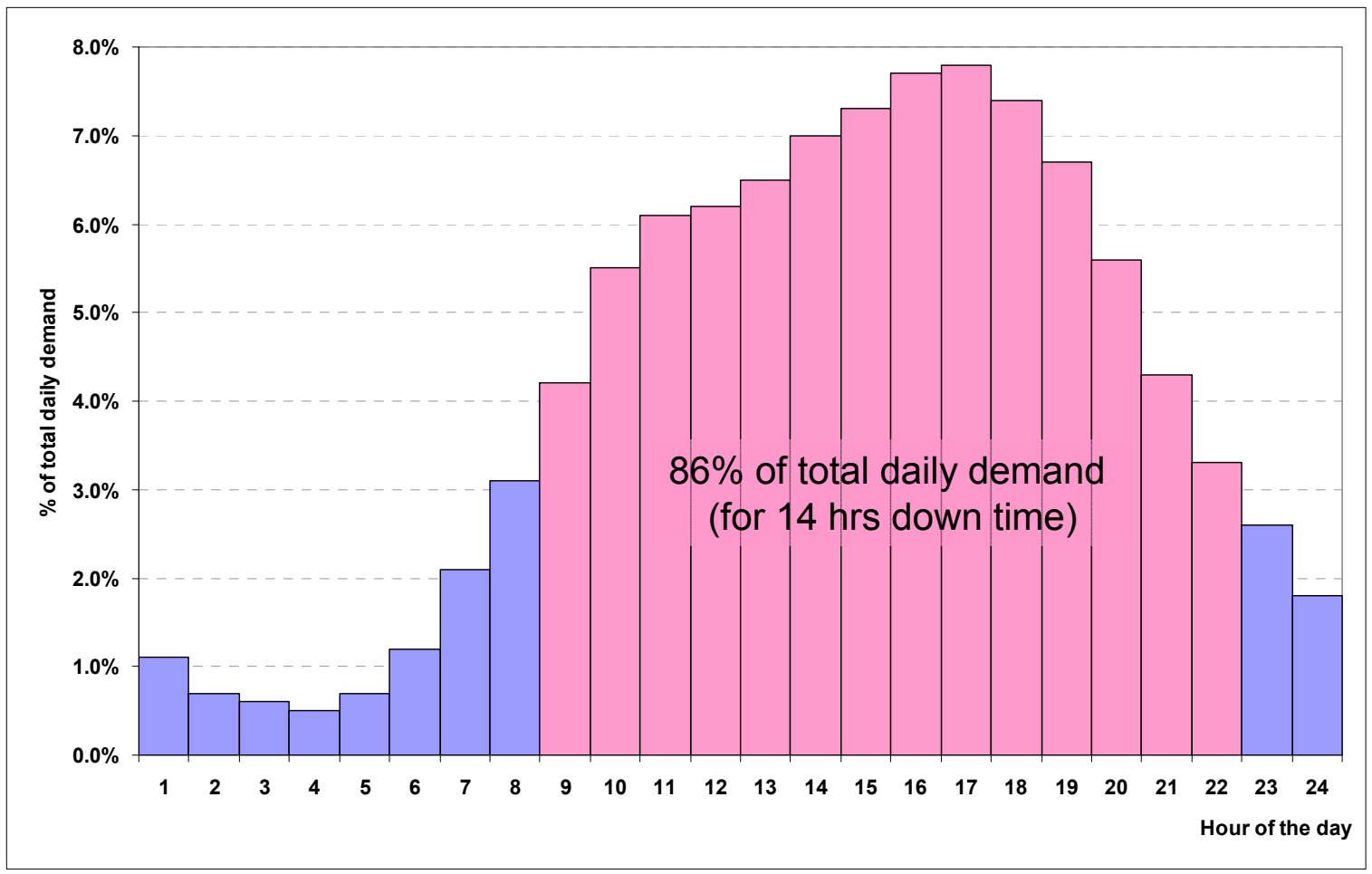

Figure 14. Critical 14 hours of supply interruption 
Using the $\mathrm{H} 2 \mathrm{~A}$ default demand profiles, the usable storage required to satisfy the daily and hourly peak in demand, as well as the unscheduled production outages can be calculated as follows.

Usable Storage $(\mathrm{H} 2 \mathrm{~A}$ default $)=[13 \%+\max (1 / 3,6 / 7)] \mathrm{x}$ summer daily demand $=99 \%$ of summer daily demand

$\approx 1$ summer daily demand (i.e. $\approx$ daily production capacity) 


\section{Appendix C. Reviewer Biographies}

\section{Joseph E. Genovese}

Joe Genovese is a retired research and development engineer with 39 years experience at Hamilton Sundstrand, Division of United Technologies Corporation. Prior to being named a Technical Fellow in 2004, he was the Chief of Advanced Technology for the Space Systems International business unit. Joe led a group of research and development engineers designing, developing, and producing water electrolyzers based on the use of the proton exchange membrane technology as well as advanced $\mathrm{CO}_{2}$ sorbents for life-support applications.

Joe is an aerospace engineer and holds a master's degree in astronautics and chemically reacting flow, from the Polytechnic Institute of New York. The Board of Directors of the United Technologies Corporation awarded Joe the Mead Medal for Technical Excellence. He is the author of eight technical papers and hold nine U.S. patents covering a range of propulsion, lifesupport, and electrolysis topics.

\section{Knut Harg}

Knut Harg is a private consultant based in Skien, Norway. He previously held the position as president of Hydrogen Technologies AS (previously Norsk Hydro Electrolysers AS), one of the leading global suppliers of electrolyzers for hydrogen production. Knut is a chemical engineer, and holds degrees from the Norwegian Institute of Technology and from the University of Wisconsin at Madison. He was employed by the energy and materials group Norsk Hydro ASA for more than 30 years, and has held management positions in research, engineering, and business development.

Knut has conducted presentations on electrolysis and hydrogen at several international conferences, most recently chairing a roundtable discussion on hydrogen at the 2008 World Petroleum Congress in Madrid. He has also been invited by the DOE to contribute to discussions about programs regarding water electrolysis. Through his position as president of Hydrogen Technologies, Knut was responsible for HyNor (the Norwegian Hydrogen Highway project), for the Utsira project (the world's first hydrogen-based community), and for extensive product developments in both PEM and alkaline electrolysis. Knut is a member of the Scientific Committee for the European "Joint Undertaking on Fuel Cells and Hydrogen".

\section{Mark Paster}

Mark Paster has more than 12 years of experience in sustainability analysis and technology research and development, with emphasis on energy issues, renewable energy, and the use of biomass. He has had a distinguished career in technology development and economic analysis with extensive breadth and depth of experience in all aspects of industrial R\&D through 27 years of experience at Monsanto. Mark has 7 years of experience as a technology development manager in the DOE Office of Energy Efficiency and Renewable Energy at the Department of Energy, and more than 5 years of experience at DOE managing the development and analysis of hydrogen production and delivery technologies. Production technologies included electrolysis, natural gas reforming, biomass gasification, and high temperature solar driven thermo-chemical cycles. Delivery technologies included gaseous pipelines and truck delivery, cryogenic liquid truck delivery, and the use of novel hydrogen carriers. Mark is a chemical engineer with an M.S. from Princeton University and a B.S. from the University of Pennsylvania. 


\section{John A. Turner}

John Turner, $\mathrm{PhD}$, is a Research Fellow at the National Renewable Energy Laboratory. He received his B.S. degree from Idaho State University, his Ph.D. from Colorado State University, and completed a postdoctoral appointment at the California Institute of Technology before joining the Laboratory (then the Solar Energy Research Institute) in 1979. His research is primarily concerned with enabling technologies for the implementation of hydrogen systems into the energy infrastructure. This includes direct conversion (photoelectrolysis) systems for hydrogen production from sunlight and water, materials for advanced fuel cell membranes, and corrosion protection for fuel cell metal bipolar plates. Other work involves the study of electrode materials for high energy density lithium batteries and fundamental processes of charge transfer at semiconductor electrodes. He is the author or co-author of over 120 peer-reviewed publications in the areas of photoelectrochemistry, fuel cells, batteries, general electrochemistry and analytical chemistry. 